\title{
Postmenopausal Health and Disease from the Perspective of Evolutionary Medicine
}

\author{
Andrew W. Froehle \\ Department of Community Health \\ Boonshoft School of Medicine \\ Wright State University
}

\begin{abstract}
Menopause normally occurs between 45-55 years of age, marks the end of a woman's reproductive lifespan, and is accompanied by a reduction in estrogen that has substantial physiological effects. The standard medical view is that these changes underlie high postmenopausal disease rates, defining menopause as an estrogen deficiency condition needing treatment. This view stems from the idea that extended postmenopausal longevity is a consequence of recent technological developments, such that women now outlive their evolutionarily-programmed physiological functional lifespan. Increasingly, however, researchers employing an evolutionary medicine framework have used data from comparative demography, comparative biology, and human behavioral ecology to challenge the mainstream medical view. Instead, these data suggest that a two-decade human postmenopausal lifespan is an evolved, species-typical trait that distinguishes humans from other primates, and has deep roots in our evolutionary past. This view rejects the inevitability of high rates of postmenopausal disease and the concept of menopause as pathology. Rather, high postmenopausal disease risk likely stems from specific lifestyle differences between industrialized societies and foraging societies of the type that dominated human evolutionary history. Women in industrialized societies tend to have higher estrogen levels during premenopausal life, and experience a greater reduction in estrogen across menopause than do women living in foraging societies, with potentially important physiological consequences. The anthropological approach to understanding postmenopausal disease risk reframes the postmenopausal lifespan as an integral period in the human lifecycle, and offers alternative avenues for disease prevention by highlighting the importance of lifestyle effects on health.
\end{abstract}

Keywords: ${ }^{* *}$

\section{INTRODUCTION}

Anyone seeking to learn more about the subject of menopause ${ }^{1}$ will find standard clinical and public health policy interpretations readily and prominently available. A simple Internet search for the word "menopause" returns numerous websites from reputable online medical resources $^{2}$, all of which provide roughly the same, narrow definition: menopause is the complete cessation of menstruation, and occurs twelve months after the final menstrual period, usually between 45-55 years of age. Along with these definitions, much of the accompanying health information addresses symptoms, risk for associated diseases, and treatment options. This information fits the overall medical paradigm that menopause is not simply a transition between physiologically distinct life history periods, but is instead a deficiency disease that calls for allopathic treatment (Marnocha et al. 2011; Meyer 2001; Meyer 2003)

Epidemiological evidence indeed shows that the period surrounding and following menopause is associated with an increased prevalence of disease and disease risk factors, particularly those relating to the metabolic syndrome including weight gain, body composition change, obesity, hyperlipidemia, hypertension, and insulin resistance, all of which increase risk for heart attack, stroke, and type 2 diabetes (Torrens et al. 2009; Enns and Tiidus 2010). In the 
United States, 39.8\% of women aged 45-64 years are obese, $39.7 \%$ are hypertensive, and $11.3 \%$ are diabetic, whereas rates for the same conditions among women aged 20-44 years are $33.2 \%, 6.9 \%$ and $3.2 \%$, respectively(3) 3 . Of all new type 2 diabetes diagnoses in U.S. adults over age 20 years, 55\% occur in the 45-64 year age range, with an additional $20 \%$ occurring after age 65 years (Centers for Disease Control and Prevention (CDC) 2011).

The medical deficiency disease model attributes elevated disease prevalence to the substantial and permanent reduction in circulating levels of the reproductive steroid hormone 17 $\beta$-estradiol (henceforth referred to as simply estrogen) that occurs within the four years surrounding the final menstrual period (Randolph et al. 2011; Sowers et al. 2008). Estrogen has multiple non-reproductive physiological functions including fat metabolism for energy, and is involved in numerous metabolic signaling pathways (Campbell and Febbraio 2001; Campbell et al. 2003; Spangenburg, Geiger et al. 2012; Sugiyama and Agellon 2012). Thus, increased rates of metabolic diseases in menopausal and postmenopausal women are thought to result in large part from the menopausal reduction in circulating estrogen and the ensuing hyposteroidal physiological environment (Carr 2003). In the medical model, the female body is poorly equipped to maintain normal metabolic function under reducedestrogen conditions, and the postmenopausal period represents a state of "...uncontrolled degenerative loss of homeostasis..." (Austad 1997).

The idea that the female body is ill-prepared to function in the low-estrogen postmenopausal physiological environment derives from a specific view of the human lifespan, which holds that developments in hygiene, sanitation, and medical technology have only recently extended the normal human lifespan into the 6th and 7th decades of life, beyond the evolutionarily programmed physiological lifespan. In other words, these technological developments have resulted in humans "living too long", and outlasting our intrinsic capacity for physiological self-maintenance. This perspective relies on the concept that somatic longevity, the lifespan of non-reproductive physiological systems, mirrors reproductive longevity, or the lifespan of germline cells that allow one to reproduce. Menopause represents the termination of reproductive longevity, which, implicit in the medical view, means that evolution has programmed the maintenance of somatic longevity to cease at this same point. In other words, somatic systems are expected not to have evolved to function past menopause, and are thus incapable of adapting to the hyposteroidal postmenopausal environment. This view lends a character of inevitability to the medical conception of postmenopausal disease, and suggests that women simply live longer than their bodies are built to handle.

The main consequence of the medical deficiency disease model of menopause has been the extensive prescription of hormone replacement therapy (HT), with the intention of replacing lost estrogen to reduce symptoms and prevent development of disease. The promotion of HT as treatment serves as a thorough illustration of the medicalization of menopause, as demonstrated by a recent survey of HT-related pharmaceutical literature. Websites for HT generally cast menopause as having unnatural, negative effects and leading to suffering, not only physically, but also psychologically and socially, and present the physician's perspective as privileged, versus women's own experiences (Charbonneau 2010). Widespread prescription of HT as the solution to the medical problem of menopause in and of itself provides ample reason to seek alternative conceptions of the relationship between menopause and women's health. This is because over the past decade, a series of papers reporting the results of the Women's Health Initiative (WHI) and the Million Women Study have demonstrated an association between taking HT and increased risk of developing cardiovascular disease and breast cancer (Narod 2011; Rossouw et al. 2002). Although these results have been debated since their publication (Tanko and Christiansen 2006; Utian 2012; Shapiro 2004), the rate of women taking HT has since declined (Ettinger et al. 2012).

While decreased HT use represents a modest shift away from the emphasis on pharmaceutical responses to menopause, it appears mainly to be due to women's choices rather than a change in the medical model (Marnocha et al. 2011). Instead, the medical model appears to remain intact, as evidenced by the HT advertising discussed above (Charbonneau 2010), by the reflexive readiness of physicians to prescribe HT (Marnocha et al. 2011), and by efforts in the scientific community to promote HT by citing criticism of the WHI's results (Nedergaard et al. 2013). Whereas women can reduce the physical consequences of the medical model by choosing not to fill HT prescriptions, the continued medicalization of menopause still has important and often negative social and psychological effects on women (Cimons 2008; Charbonneau 2010; Marnocha et al. 2011).

This paper presents an alternative approach to understanding menopause and postmenopausal health, that of evolutionary medicine, which follows from the principle that modern human health and disease are at least partially products of the evolutionary forces that have shaped modern human biology and variation (Nesse and 
Williams 1994; Williams and Nesse 1991; Gammelgaard 2000). As such, the following evidence serves as a critique of the medical model of menopause as a deficiency disease, supporting a different, evolutionary view that situates human menopause and the postmenopausal lifespan in its broader ecological and life history contexts. The evolutionary view derives from a wealth of comparative anthropological and biological evidence, incorporating cross-cultural and cross-species comparisons to more holistically understand the process of menopause and health expectations for the postmenopausal lifespan. Adopting the evolutionary perspective has the potential to change clinical practicein two key ways. The firstis to further obviate the routine prescription of HT by establishing that extended maintenance of sound physiological function under low-estrogen postmenopausal conditions is the human norm. In other words, somatic and reproductive longevity are divorced, so that the human female body has evolved to function and remain healthy for a substantial period of time after menopause, despite the accompanying reduction in circulating estrogen.

Second, comparisons of menopausal physiology, postmenopausal survival, and health across species and between human cultures allows for the identification of lifestyle and behavioral factors that may play a role in the etiology of metabolic diseases among women living in industrialized societies, presenting non-pharmacological and non-hormonal avenues for disease prevention. Although there is a vast literature on the physiology of metabolic disease, detailing the relevant physiochemical pathways and mechanisms of preventive strategies is beyond the scope of this paper. Instead, the following sections review the evidence for evolutionary medicine's interpretation of menopause, which can point to promising areas of research into the specific physiological mechanisms that promote postmenopausal health. Overall, this paper contends that the medical paradigm of deficiency disease is out of step with the biological reality of human menopause, and that an evolutionary medicine approach has the potential to enhance medical, cultural, and individual understandings of menopause and the postmenopausal lifespan.

\section{The Process of Menopause and its Relationship to Postmenopausal Health}

An important aspect of the evolutionary medicine approach is the recognition that menopause is the culmination of a long-term, highly-variable process, rather than a brief transition or event, as sometimes characterized in the medical model. The length of the menopausal process contributes to its variability and also to variability in postmenopausal physiology, providing the raw material upon which natural selection acts. Also important to recognize is that menopause, defined as the end of menstruation, is better seen as the culmination of a larger and longer process wherein ovulation ceases and reduces fecundity, or reproductive potential, to zero. This larger process of the cessation of ovulation, in which menopause is the most readily observable outcome, places a limit on lifetime reproductive success, which is the key variable in natural selection. Evolutionary interpretations of menopause must therefore incorporate an understanding of variation in the process of menopause and its relationship to reproductive potential.

The capacity to experience menopause is dependent on the property of semelgametogenesis, where all reproductive cells (in this case oocytes, or egg cells) are overwhelmingly produced only early in life, and are not replenished at any point later in the lifespan (Finch 1990; Peccei 2001b; Ellison 2010). Human females are semelgametogenic, a trait they share with all other female mammals and birds (Bribiescas 2006), and human oocyte production occurs largely prior to birth (but see (White et al. 2012) with the number of egg cells peaking during the fifth month of gestation. Thereafter, due to atresia (a form of apoptosis, or programmed cell death) the population of oocytes decreases to roughly two million at birth, and 400,000 at puberty. After puberty, ovulation and continued atresia cooperate to deplete the remaining store (Faddy et al. 1992; Hansen et al. 2008), eventually reaching a threshold of $~ 1000$ surviving ova in the years leading up to menopause. Below this threshold, the remaining oocytes produce very little estrogen, which is required to stimulate uterine wall preparation in anticipation of implantation of the mature egg (Clancy 2009).

Among other hormonal changes, the menopausal reduction in estrogen is thought to disrupt endocrine pathways responsible for ovulation and thus fecundity, leading to an average age at menopause between $~ 45-55$ years across human populations (O'Connor et al. 1998; Thomas et al. 2001; Greenspan and Gardner 2004; Johnson et al. 2004; Walker et al. 1984). The age at menopause does, however, vary on population and individual scales, owing to a combination of genetic, environmental and behavioral factors. On the whole, data from diverse human populations consistently fall within the aforementioned age range (see Figure 1). The three lowest population average ages at menopause ( $\leq 47$ years), however, all come from subsistence farming or herding populations practicing natural fertility (i.e. non-contracepting), suggesting that nutritional and reproductive factors influence menopausal timing. 


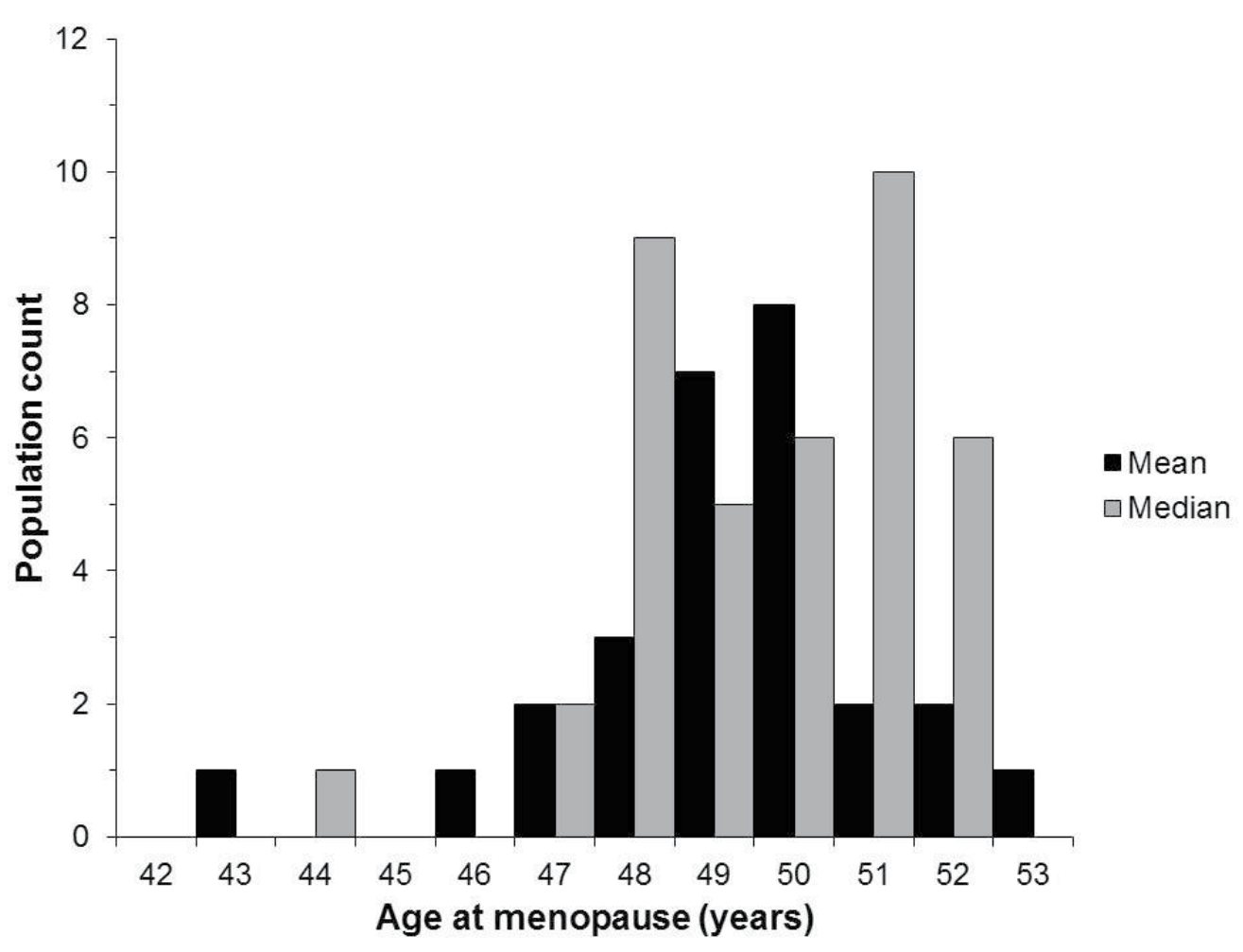

Figure 1: Number of populations (total $N=53$ ) with average (mean and median) ages at natural menopause within each age range (Adekunle et al. 2000; Ayatollahi et al. 2003; Beall 1983; Castelo-Branco et al. 2005; Chim et al. 2002; Garrido-Latorre et al. 1996; Gonzales et al. 1997; Ku et al. 2004; Mohammad et al. 2004; Balan 1995; Okonofua et al. 1990; Reynolds and Obermeyer 2003; Walker et al. 1984; Castelo-Branco et al. 2006; Burch and Gunz 1967; Chow et al. 1997; Fuchs and Paskarbeit 1976; Greer et al. 2003; Hunt, Jr. and Newcomer 1984; Ismael 1994; Kapoor and Kapoor 1986; Karim et al. 1985; Kato et al. 1998; Kriplani and Banerjee 2005; Kono et al. 1990; Kwawukume et al. 1993; Luoto et al. 1994; Magursky et al. 1975; McKinlay et al. 1985; Morabia et al. 1996; Ramoso-Jalbuena 1994; Reynolds and Obermeyer 2001; Rizk et al. 1998; Samil and Wishnuwardhani 1994; Tungphaisal et al. 1991; Walsh 1978; Carda et al. 1998; Hagstad 1988; Scragg 1973).

Whereas the medical model would tend to view such variation and deviations from the norm as pathological (Meyer 2001), the evolutionary perspective sees this variation as potentially adaptive (Gluckman and Beedle 2007; Ellison 2010). Given that the process of oocyte depletion occurs over decades and across several very distinct life history periods, it is possible that variation in age at menopause and postmenopausal physiology may be optimized for an individual in the mode of a predictive adaptive response (Gluckman and Beedle 2007; Gluckman et al. 2005). The "predictive adaptive response" concept suggests that individual and population-level phenotypic variation reflects an evolved flexibility that responds to cues during development, influencing subsequent life history and geared towards maximizing lifetime fertility in the face of an unstable, yet to some extent predictable, environment. This approach has been used extensively to explain variation in menstrual cycle characteristics
(Vitzthum 2008; Vitzthum 2009), and in a similar manner may be applicable to menopause and the postmenopausal lifespan (Ellison 2010). In this view, variation in the process of menopause and postmenopausal physiology represents the normal range of phenotypic expression, within constraints set by the specific evolutionary history of the human species.

On top of population-level variation, there is also substantial inter-individual variation within populations in terms of the slowing of reproductive function and age at menopause (Treloar 1981; te Velde and Pearson 2002). Some of this variation is inherited, with heritability estimates ranging from 30-85\% (Torgerson, Thomas, Campbell et al. 1997; Torgerson, Thomas, and Reid 1997; Peccei 1999; de Bruin et al. 2001; van Asselt et al. 2004; Murabito et al. 2005; Snieder et al. 1998), but such estimates should be interpreted conservatively (Vitzthum 
2003; Voorhuis et al. 2010). Thus, the genetic basis for menopause remains incompletely understood (Voorhuis et al. 2010) despite extensive research on the genetics of aging more generally (Finch 1990; Finch and Kirkwood 2000). Still, the inconsistency between samples can be taken to mean that age at menopause is a complex (nonMendelian) trait, under the influence of multiple genetic and environmental factors.

The effects of environmental, behavioral, and developmental influences on the age at menopause are somewhat better-known. Cigarette smoking is associated with an earlier age at menopause (Zenzes 2000; Mishra et al. 2010), whereas women who experience fewer menstrual cycles throughout life due to greater parity or more irregular cycles tend to have a later age at menopause (Soberon et al. 1966; Kaufert et al. 1987; Stanford et al. 1987; Whelan et al. 1990; Dahlgren et al. 1992; Torgerson et al. 1994; Cramer et al. 1995; vanNoord et al. 1997). Socioeconomic indicators including level of education and income may affect age at menopause, but results are highly inconsistent, likely owing to a large number of uncontrolled confounding variables (Mohammad et al. 2004; Flint 1974; Beall 1983; Kaufert et al. 1987; Weinberg et al. 1989; Torgerson et al. 1994; Garrido-Latorre et al. 1996; Gonzales et al. 1997; vanNoord et al. 1997; Chim et al. 2002; $\mathrm{Ku}$ et al. 2004; Castelo-Branco et al. 2005; Walker et al. 1984; Okonofua et al. 1990; Gonzales et al. 1997; Reynolds and Obermeyer 2003; Mohammad et al. 2004; Kriplani and Banerjee 2005). Studies of birth weight and early postnatal growth suggest that developmental conditions can also affect age at menopause, but again, the aggregate results fail to point to a consistent relationship (Mishra et al. 2007; Cresswell et al. 1997; Hardy and Kuh 2002; Hardy and Kuh 2005; Tom et al. 2010; Sloboda et al. 2011; Elias et al. 2003).

Although continued research is needed to precisely define the major factors that influence menopause, it is clear that the timing and process of menopause are quite variable, and receive inputs from both external and internal environmental factors. The variability and heritability of the timing of menopause provide the raw material from which adaptations evolve, and part of the menopausal adaptation in humans appears to have been the retention of flexibility as part of an overall ovulatory predictive adaptive response mechanism, aimed at maximizing reproductive success. This flexibility may predispose different women to varying metabolic profiles after menopause, differentiating between levels of function and disease risk in the low-estrogen postmenopausal environment. As seen below, however, the evolutionary evidence also points to selection for extended somatic maintenance well-into the postmenopausal period, which may have also evolved as a method of increasing lifetime reproductive success.

\section{Evolutionary Views of the Postmenopausal LifESPAN: PARADOX OR AdAPTATION?}

Before discussing the postmenopausal lifespan specifically, it is important to understand how biologists conceptualize the more general issue of aging, defined not simply as the accrual of time spent living, but as the loss of function in physiological systems with increasing age (Gavrilov and Gavrilova 2006). Aging in and of itself has long been a problematic concept for evolutionary biology (Weismann 1889; Medawar 1952), since theoretically the most reproductively successful organisms should be those that live forever and never cease to reproduce. Why should selection allow for functional deterioration and the regular occurrence of intrinsic causes of mortality (i.e. death due to failure of internal physiological systems rather than succumbing to extrinsic sources of mortality such as predation), rather than favoring self-maintenance in perpetuity, so long as organisms can avoid extrinsic mortality factors? Reproductive decline, in particular, requires explanation from the standpoint of natural selection (Williams 1957), since reducing fecundity to zero curtails reproductive success and is of no apparent selective value.

The prevailing theory of aging posits that the rate of intrinsic senescence in physiological systems results from the interaction between the population-specific rate of extrinsic-cause mortality (e.g., predation) and age-specific fertility potential (Medawar 1952; Williams 1957; Hamilton 1966; Charlesworth 1994). For any age cohort, the number of individuals left alive at a particular age to pass on genes, and the offspring those remaining individuals will potentially produce as a fraction of total offspring production for that cohort, will determine the force of selection of any gene acting at that particular age. At ages where most individuals are still alive and only a small proportion of potential offspring have been produced (such as shortly after puberty), selection to minimize intrinsic mortality is very high. In contrast, at ages where many individuals from a cohort have fallen to accidental death, predation, disease, or other extrinsic factors, and when most of the likely offspring for that cohort have already been produced, then the strength of selection to maintain somatic integrity against intrinsic sources of mortality is much lower, since it has little effect on subsequent generations' ability to reproduce (Williams 1957; Hamilton 1966; Kirkwood 1977; Kirkwood 1980; Kirkwood and Holliday 1979). 
Intrinsic challenges to somatic integrity arise as inborn biochemical byproducts of multiple physiological processes. For example, errors in cellular division, DNA replication, and protein synthesis (Kirkwood 1977; Kirkwood and Holliday 1979; Kirkwood 1980) can occur easily and challenge somatic viability, so that organisms invest considerable energy in mechanisms that increase accuracy in these processes. Such mechanisms are, however, only maintained as long as required to ensure that genes are successfully passed on to offspring at a population-specific rate. With increasing age, higher error rates in these processes lead to accumulation of dysfunction, disruption of physiological systems, and ultimately death (Kirkwood and Shanley 2010).

Challenges to somatic integrity can also arise as a result of antagonistic pleiotropy, where individual genes have positive effects early in life prior to and during the peak reproductive period, but have detrimental effects later in life (Williams 1957). This occurs because genes that promote viability and reproductive success early in life, when much reproductive potential remains, will be strongly selected for, but will be only weakly selected against if they exert negative effects later in life, when fewer individuals remain alive and little if any reproductive potential remains. In fact, menopause itself and the resultant low estrogen environment may be products of antagonistic pleiotropy (Crews 2003). Genes that promote higher circulating estrogen levels during the reproductive years have likely been selected for, since they play a major role in stimulating ovulation and thus raise fecundity. This same process, however, leads to more rapid depletion of oocyte stores, and therefore menopause, after which the ovary drastically reduces estrogen production and poses significant challenges to maintaining the somatic integrity of metabolic and cardiovascular systems.

This sharp increase in disease risk after menopause is in agreement with the overarching biological perspective on aging. Maintaining somatic viability after menopause is anathema to the evolutionary process, so much so that Hamilton (Hamilton 1966) predicted a so-called "wall of death", where intrinsic mortality would increase sharply upon the loss of reproductive capacity. In the same paper, however, Hamilton also noted that humans fail to meet the "wall of death" prediction, with much more gradual mortality rates past the age of menopause than expected from theory. Thus, the human postmenopausal lifespan and its relative rarity in the living world present a theoretical paradox for evolutionary biology. The problem lies in the apparent disconnect between the reproductive lifespan and somatic longevity: if differential reproductive success is the key functional outcome of evolution, then why would human females have evolved to maintain non-reproductive physiological function for decades past the termination of ovulation? The assumption that somatic and reproductive longevity are closely linked is at least implicit in the medical model of menopause and postmenopausal health.

Evolutionary biologists, on the other hand, have addressed several key questions in attempting to explain this paradox, the evidence for which is summarized below. First, are aging patterns in human somatic and reproductive systems disjointed only under conditions like those of industrialized societies, or is the pattern shared across diverse socioeconomic environments? Second, do humans differ from other animals, especially closely-related primate species, in the process of menopause and the postmenopausal lifespan? If the pattern of postmenopausal survival seen among women in industrialized society is in fact shared by women in other types of societies, and if this differs from other primates, how and why might the unique human pattern have arisen? Most importantly, what are the consequences of the answers the evidence provides for health expectations among postmenopausal women living today and in the future, and what do these data mean for the current prevailing medical model?

\section{Comparative Demography}

Demographic data show clearly that a high rate of multi-decade postmenopausal survival occurs in human populations living under non-industrialized conditions, and lacking access to medico-technological developments, thus challenging the medical model's notion that a long postmenopausal lifespan is only a recent, technological development. Changes in mortality and survivorship from 1850 to 2000 among females in the United States illustrate this point well. Whereas major changes in sanitation, hygiene and medical technology that occurred from the late 19th century to the present (Cutler and Miller 2005) have dramatically increased infant and childhood survivorship (Gray 1976), they have had much more modest effects on the postmenopausal lifespan. Survivorship rates from birth to age 15 years (a proxy for sexual maturity) and from birth to age 45 years (a proxy for age at menopause) have risen from $\sim 65 \%$ to $\sim 100 \%$ and from $\sim 50 \%$ to $\sim 95 \%$, respectively, over the past 150 years (Figure 2). The proportion of women living to age 15 that then also survived to age 45 , meanwhile, increased from $\sim 70 \%$ to $\sim 95 \%$. Whereas life expectancy at birth has doubled over that same time period, the average amount of life remaining at age 45 has only increased from $\sim 25$ years to $\sim 35$ years, with most of the increase occurring after 1940 (Figure 3). Thus, despite modest gains in the past 150 


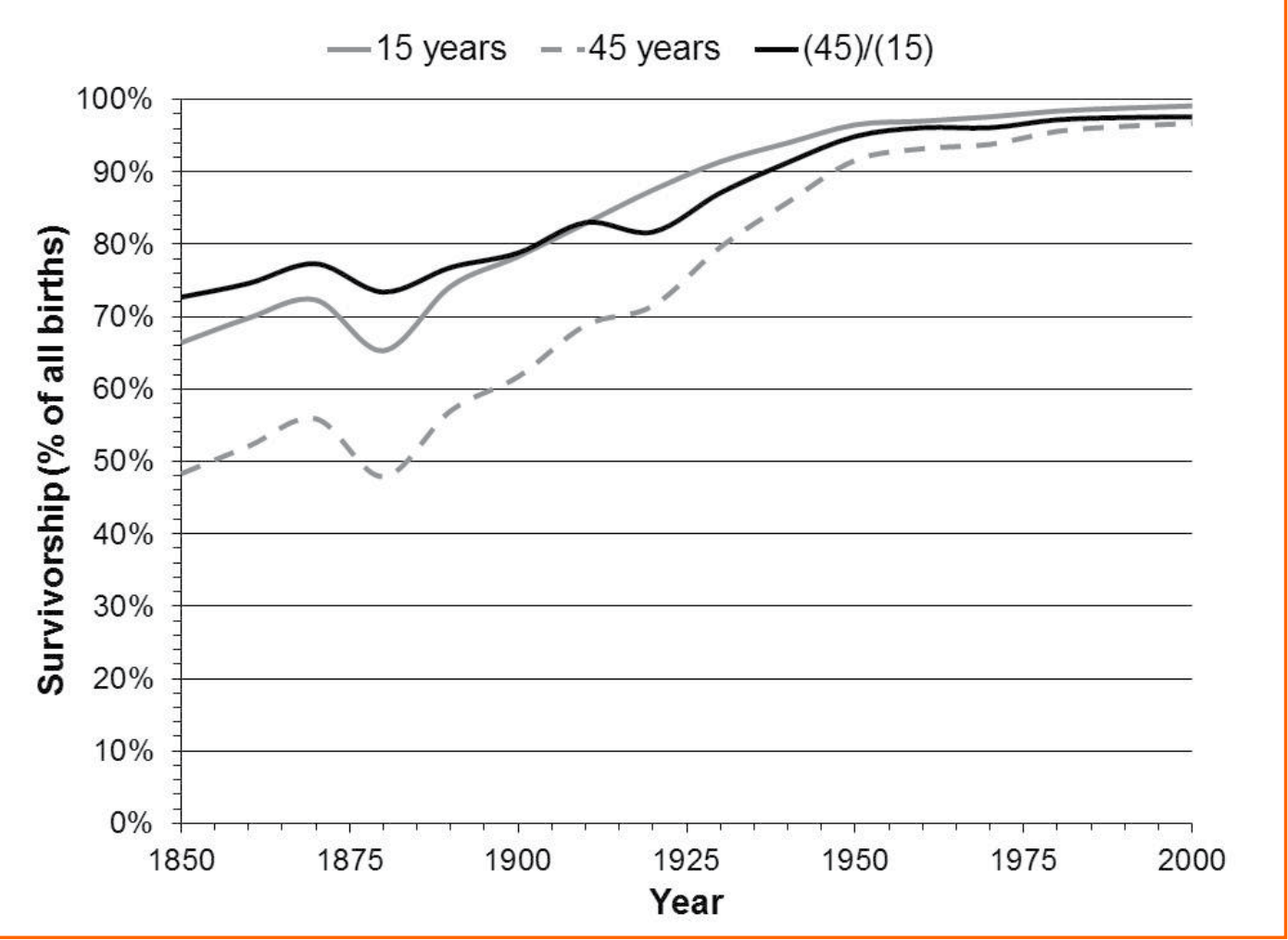

Figure 2: Survivorship from birth to age 15 years (solid gray line) and birth to age 45 years (dashed gray line); conditional survivorship from 15-45 years (black line: rate at which individuals who survived to age 15 also survived to age 45). Life table data for 1850-1890 (Haines 1994) and for 19002000 (Bell and Miller 2005).

Figure 3: L.E. = Life expectancy, or average years of life remaining at a specific age. Life table data for 1850-1890 (Haines 1994) and for 19002000 (Bell and Miller 2005). 


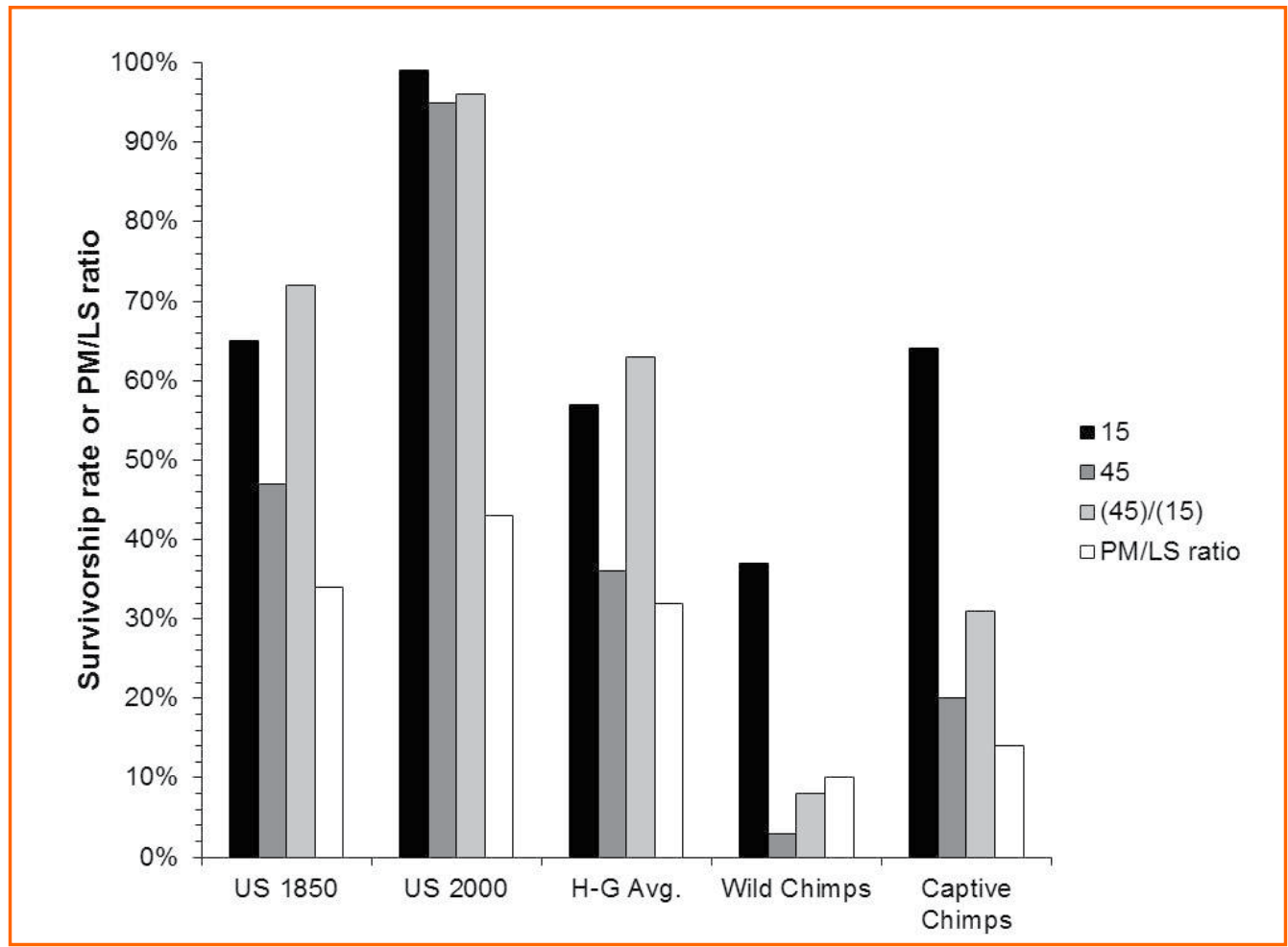

Figure 4: Survivorship from birth to age 15 years (black bars) and birth to age 45 years (dark gray bars); conditional survivorship from 15-45 years (light gray bars); and PM/LS ratio, the average postmenopausal lifespan (PM) remaining at age 45 years as a percentage of total lifespan (LS), calculated as e45/(e45+45), where e45 is the life expectancy at age 45 years. United States (US) data for 1850 (Haines 1994) and for 2000 (Bell and Miller 2005); hunter-gatherer (H-G) and chimpanzee data (Gurven and Kaplan 2007).

years, even in 1850 prior to greater sanitation, hygiene and medical technology, over two-thirds of women fortunate enough to live to age 15 could expect to live to age 45 , and to then survive an average of another 25 years, or $35 \%$ of the total lifespan.

Demographic data from five hunter-gatherer groups (Gurven and Kaplan 2007) support the idea that this pattern of postmenopausal survival is a widely-shared human trait. Despite immense diversity (Kelly 1995; Panter-Brick et al. 2001), hunter-gatherer societies share general characteristics that make them good models for mortality and survivorship in non-industrial, nonagricultural people. Although hunter-gathers are modern humans living in the modern world, and are thus not our "ancestors", the manner in which they live approximates in some critical ways the activity patterns and nutritional and reproductive conditions that may have prevailed over the vast majority of human evolutionary history. Huntergatherers obtain food from seasonally fluctuating wild plant and animal supplies, practice natural fertility, and lack reliable access to antibiotics, immunizations, water treatment, and other developments that increase life expectancy at birth in industrialized societies (Wood 1994; Panter-Brick 2002; Blurton Jones et al. 2002; Gurven and Kaplan 2007). As such, hunter-gatherers are expected to differ in terms of mortality and survivorship rates from populations living under agricultural and industrialized conditions.

Nonetheless, hunter-gatherer survivorship and life expectancy patterns are remarkably similar to the pre-industrial United States (Figure 4). In both cases, high rates of infant and juvenile mortality result in life expectancy at birth of less than 40 years and 57-65\% survivorship from birth to age 15 . For those who live to sexual maturity, however, $\sim 65 \%$ will also reach age 45 and on average survive for another two decades. The data therefore strongly suggest that even under divergent socioeconomic conditions, a substantial proportion of all females born, and an even greater proportion of those who live to reproductive adulthood, share the expectation of multi-decade postmenopausal survival, amounting to on average a third of the total lifespan. 


\section{Comparative Biology}

Whereas comparative demography points to biological similarities between all humans, regardless of socioeconomic environment, comparative biology can place the human pattern of postmenopausal survival in its proper evolutionary context. Note that Figure 4 also includes survivorship data from wild and captive chimpanzees (addressed in detail below). As our closest living relatives (Goodman et al. 1998), the panins (common chimpanzees: Pan troglodytes spp.; bonobos: Pan paniscus spp.) provide critical information as to which traits humans share with other primates, and which traits likely evolved since the split with our last common ancestor. Comparative biological data can address whether the human pattern of postmenopausal survival is unique or common among some larger taxonomic grouping. As shown below, although a few individual animals in many species may briefly outlive menopause (Cohen 2004) and some whale species exhibit a postmenopausal lifespan similar to humans (Kasuya and Marsh 1984; Marsh and Kasuya 1984; Marsh and Kasuya 1986; Olesiuk et al. 1990; Bloch et al. 1993; Martin and Rothery 1993; McAuliffe and Whitehead 2005; Foote 2008), overall humans are unique among mammals, including primates, and are evolutionarily derived relative to panins in having specieswide, common, multi-decade survival past menopause (Caro et al. 1995; Packer et al. 1998; Bronikowski et al. 2002; Pavelka and Fedigan 1999; Bellino and Wise 2003; Cohen 2004; Fedigan and Pavelka 2006).

The first question is whether human postmenopausal longevity has been achieved by foreshortening the reproductivelifespan, orby extension of thesomaticlifespan relative to our last common ancestor. Overwhelmingly, the evidence supports the latter conclusion: modern humans share an average age at menopause with panins, but have the capacity to live well beyond menopause due to an extension of somatic longevity. Evidence for a shared human/panin menopausal process, and an age range for the cessation of ovulation of 45-55 years (Walker and Herndon 2008), comes from studies of both wild and captive chimpanzees and bonobos, with data on ovarian histology and reproductive hormones, menstruation and sexual swellings (swellings of the anogenital region that signify ovulation and are a proxy for estrogen activity), and age-specific fertility. First, from examinations of ovarian histology, humans and panins share a similar trajectory of oocyte reduction (Gould et al. 1981; Leidy et al. 1998; Hansen et al. 2008; Videan et al. 2008; Jones et al. 2007) that proceeds at essentially the same rate in both taxa (Jones et al. 2007). As in humans, the reduced oocyte population is related to hormonal changes in panins, and reproductive hormone profiles of panins from their late 30 s to age 50 resemble those of pre- and perimenopausal women of the same age (Gould et al. 1981; Jurke et al. 2000; Videan et al. 2006). In terms of the effects of oocyte depletion on estrogenic stimulation of ovulation and fecundity, panin menstrual bleeding and sexual swellings, which reach peak frequency, regularity, and duration of maximal tumescence in the 20s, gradually become less frequent, more irregular, and shorter until eventually ceasing altogether in the 40s and 50s (Graham 1979; Gould et al. 1981; Jurke et al. 2000; Videan et al. 2006; Lacreuse et al. 2008). Thus, it appears that humans and panins share an ancestral pattern of oocyte reduction and a similar ovulatory "dose-response" to the small remaining population of sex cells during the fifth and sixth decades of life (Hawkes and Smith 2010).

Observations of panin age-specific fertility are consistent with the data on oocyte counts, hormone profiles, and ovulatory cycling, also suggesting an end to reproductive capacity occurring between the mid-40s and mid-50s. Past age 35 , fertility declines substantially, and the proportion of pregnancies terminating in stillbirth or spontaneous abortion increases among captive chimpanzees (Graham 1979; Roof et al. 2005; Atsalis and Videan 2009b; Atsalis and Videan 2009a). Across a large sample from multiple wild chimpanzee study sites, there is a sharp drop-off in number of births per female per year between $40-44$ years old, with a tiny fraction of females reproducing up to age 55 (Emery et al. 2007).

As in humans (den Tonkelaar et al. 1998; Vitzthum 2009), there is substantial individual and population-level variation among panins in the process of reproductive aging, the age at which ovulation ceases, and the termination of fertility (Boesch and Boesch-Achermann 2000; Videan et al. 2006; Emery et al. 2007; Lacreuse et al. 2008). For example, there are isolated reports of live captive births in the late 40s (Puschmann and Federer 2008). Whether this site-based variation is physiological or due to social differences in age-related mating behavior remains undetermined, but it is entirely possible that ecological factors affect reproductive parameters similarly in both panins and humans (Atsalis and Videan 2009b; Atsalis and Videan 2009a). Although this hypothesis has not been extensively explored (Herndon and Lacreuse 2009), it points to the possibility of a shared capacity for predictive adaptive responses in the reproductive systems of the human-panin clade, and thus the variability necessary for evolutionary differentiation by natural selection.

Overall, however, due to mortality patterns, menopause occurs in a very small proportion of all female panins 
born, and then usually only very late in life (Herndon and Lacreuse 2009; Lacreuse et al. 2008), but there is also variation in the rate at which panins survive past menopause (Hill et al. 2001; Videan et al. 2006; Emery et al. 2007; Atsalis and Videan 2009b; Atsalis and Videan 2009a; Herndon and Lacreuse 2009). To some extent, mortality differences between captive and wild chimpanzees mirror differences between human populations living under different socioeconomic circumstances (i.e. reduced infant mortality and greater survivorship due to nutritional security and decreased risk of extrinsic mortality). Even in captivity, however, most benefits of reduced extrinsiccause mortality accrue as increased survivorship to age 15 (a good proxy for sexual maturity in chimpanzees as in humans: (Hill et al. 2001), with a relatively small proportion of females born survive past menopause, and then only briefly (see Figure 4 ). At wild sites, only $5 \%$ of all females born survive to age $45-50$, with adult mortality rates rising between 25-30 years and spiking at and beyond age 40 (Hill et al. 2001). Of those surviving to sexual maturity, less than $10 \%$ survive to age 45 , at which point they have only $10 \%$ of their total lifespan remaining (Gurven and Kaplan 2007)2007).

Although extrinsic mortality risk likely differs between wild panins and human hunter-gatherers, much of the inter-species difference in survivorship and longevity past menopause may result from differences in the rate of aging in somatic physiological systems. Critically, although overall mortality rates are lower in captive chimpanzees, they too experience a major increase in adult mortality at roughly the same age as wild populations, implicating intrinsic rather than extrinsic causes of death (Hill et al. 2001). While adult mortality rates increase exponentially and at roughly the same rate in both chimpanzees and hunter-gatherers, the increase in mortality due to intrinsic senescence begins $\geq 10$ years earlier in chimpanzees (Gurven and Kaplan 2007). Wild chimpanzees begin to show signs of somatic aging beginning in their mid-30s, and though these outward signs of deterioration do not always correlate with incapacitation (Tarou et al. 2002; Finch and Stanford 2004), it seems plausible that they tend to succumb to intrinsic somatic senescence at earlier average ages than do humans. Possible mechanisms that explain these apparent species-level differences in intrinsic mortality and somatic longevity are discussed below.

\section{Mechanisms for Extension of the Somatic LIFESPAN}

In seeking explanations for the extension of somatic maintenance past menopause in humans, is it important to consider both the proximate physiological mechanisms by which cellular viability and functional integrity is maintained, as well as the ultimate evolutionary pressures most likely to have driven selection for an extended lifespan. The two main proximate causes of aging are the metabolic production of free radicals, which can oxidize and damage tissues and DNA (HARMAN 1956), and the accumulation of errors in DNA and its macromolecular end-products due to poor replicative control, leading to malfunctioning cells and the eventual interruption of physiological pathways (Orgel 1963; Orgel 1970; Kirkwood 1977; Kirkwood and Holliday 1979; Kirkwood 1980). Extending somatic longevity can be achieved by investing energy in mechanisms that reduce free radical production or activity, and that enhance the accuracy of protein synthesis and cellular replication.

Although somewhat limited, existing data on differences between humans and other primates in the expression of such mechanisms tends to point to greater maintenance of somatic integrity among humans. On a large scale, a reduced metabolic rate may limit free radical production and thus reduce oxidative damage (Ku and Sohal 1993; Barja et al. 1994), and humans have slightly lower than expected mass-specific metabolic rates compared to chimpanzees (Froehle and Schoeninger 2006). On a more molecular scale, blood levels of the free radical scavenger uric acid (Ames et al. 1981) tend to be higher in primates than in most mammals (Friedman et al. 1995), and are especially high in apes and humans (Wu et al. 1992; Oda et al. 2002). Humans and apes, to the exclusion of monkeys, also share mutations in the genes responsible for another group of free radical scavengers, the superoxide dismutases (Fukuhara et al. 2002), which are more active in longer-lived primate species and are most active in human organ tissues (Tolmasoff et al. 1980). In terms of DNA and fidelity in macromolecular synthesis and cellular replication, humans have higher rates of DNA repair than apes (Cortopassi and Wang 1996). Overall, then, in keeping with a longer lifespan, humans appear to have a greater physiological capacity for somatic maintenance via free-radical management and accuracy in macromolecule transcription and translation compared to other primates.

Recent research has expanded beyond the above domains to include comparative studies of other biomarkers of aging in primates. Perhaps the most extensive body of work has focused on dehydroepiandrosterone sulfate (DHEAS), an important androgen hormone with a wide variety of physiological roles, and protective effects against several metabolic and cardiovascular diseases (Lane et al. 1997). Multiple studies in rhesus monkeys (Macaca mulatta) and humans have demonstrated a decline in serum 
concentrations of DHEAS with age (Kemnitz et al. 2000; Roth et al. 2002), and an association between higher levels of circulating DHEAS and slower rates of aging (Roth et al. 2002; Lane et al. 1997). Compared to chimpanzees, human serum levels of DHEAS decline more rapidly with age, but overall concentrations are two-to-three times higher in humans at any age, and only begin to drop into the high end of the chimpanzee range at ages older than 65 years (Blevins et al. 2013). Other great ape species exhibit even lower DHEAS concentrations (Bernstein et al. 2012), consistent with the idea that higher human levels have evolved since our split with the apes and promote a unique, extended period of somatic viability. Additional research in these areas should help to clarify additional proximate physiological mechanisms by which the human lifespan is extended compared to our close primate relatives.

In terms of ultimate evolutionary mechanisms for the extension of the somatic lifespan past menopause in humans, multiple theorists (Williams 1957; Hamilton 1966) have proposed the existence of a critical breach in the so-called "wall of death". In species with relatively low lifetime fertility and high levels of long-term parental care, infant and childhood survivorship can be enhanced by traits that increase the delivery of energy to offspring. This reproductive strategy is common to most primates, and mother-child food sharing is not uncommon among panins (Ueno and Matsuzawa 2004). Humans, however, represent an extreme version of the primate pattern, with offspring that are slow-developing, energy-needy, and highly nutritionally-dependent for a much longer period of time than panins. Thus, successfully raising human offspring to sexual maturity is an exceptionally energyexpensive endeavor (Gurven and Walker 2006). To address this challenge, humans also diverge from other primates in the frequency of food sharing, the quantity of calories shared, and the breadth of regular, dyadic food sharing relationships (Kaplan and Gurven 2005).

This pattern of food sharing greatly expands the range and frequency of opportunities to indirectly boost reproductive success (i.e., through means other than producing more of one's own children), since a proportion of one's genes are shared with even distant kin. Because of these potential inclusive fitness benefits via broad-based food sharing, the human lifespan is socially selected rather than individually selected. In other words, the human lifespan serves not only to facilitate one's own direct reproductive success, but also facilitates the reproductive success of close relatives, opening up the possibility of lifespan extension via kin selection and inclusive fitness effects (Carey and Judge 2001).
This is the crack evolution requires to pry open a hole in the "wall of death": in humans, long-term parental care as well as "...altruistic contributions due to postreproductives..." (Hamilton 1966) serve as methods by which infant and childhood survivorship are increased (Williams 1957; Hamilton 1966; Lee 2008; Lee 2003). The importance of food sharing to human reproduction has thus likely added reproductive value to older adults, driving the evolution of extended somatic longevity and generating a self-reinforcing feedback loop with adult mortality. Increased fitness via food sharing at older ages would promote lower age-specific intrinsic mortality, which would in turn increase age-specific reproductive value as more individuals of older age would survive to obtain inclusive fitness benefits. This feedback would further increase the force of selection to maintain physiological function into later life (Carey and Judge 2001).

Providing for the reproductive success of offspring via food sharing plays a prominent role in hypotheses for the evolution of human longevity through effects on selective fitness. The "Mother Hypothesis" (Williams 1957; Hamilton 1966; Peccei 1995a; Peccei 1995b; Peccei 2001a; Peccei 2001b; Peccei 2005) and "Grandmother Hypothesis" (Blurton Jones et al. 2005; Hawkes et al. 1989; Hawkes et al. 1997;Hawkes etal.1998; Hawkes2003; O'Connelletal.1999) both propose that the postmenopausal lifespan evolved because it allowed women to boost lifetime reproductive success. In the former, postmenopausal mothers benefit directly by eschewing risky new pregnancies that could jeopardize the survival of existing dependent offspring. In the latter, postmenopausal women indirectly increase fitness by sharing food to promote grandchild production and survival.

Several lines of evidence support the positive effect of postmenopausal women on the reproductive success, growth, development, and survival of their children and grandchildren. In pre-industrial and modern nonindustrial agricultural societies, a maternal grandmother's presence promotes weight gain in grandchildren and increases lifetime fertility in daughters (Mayer 1981; Mayer 1982; Turke 1988; Sear et al. 2000; Sear et al. 2002; Voland and Beise 2002; Lahdenpera et al. 2004; Fox et al. 2010). Hadza hunter-gatherer grandmothers target hardto-obtain, valuable resources that their reproductivelyactive daughters are not as able to procure due to the constraints of pregnancy, nursing, and childcare (Hawkes et al. 1989; Hawkes et al. 1997; Hawkes et al. 1995; Crittenden et al. 2009). As such, childhood weight gain is positively correlated with the amount of time maternal grandmothers living in the same camp spend foraging 
(Hawkes et al. 1989; Hawkes et al. 1997).

Mathematical models also tend to find both the mother and grandmother hypotheses evolutionarily plausible. Maternal mortality has a strong enough effect on the survivorship of unweaned children, for example, to drive the extension of the lifespan past the end of fertility (Shanley and Kirkwood 2001; Sousa 2003). The mother hypothesis is, however, weakened when other potential offspring providers (e.g., fathers, aunts, uncles) are present to feed weaned children (Shanley and Kirkwood 2001; Shanley et al. 2007; Lahdenpera et al. 2011). Inclusive fitness effects accruing to grandmothers who participate in intergenerational foodsharing could also have driven lifespan extension (Shanley and Kirkwood 2001; Lee 2008; Lee 2003), with the greatest contributions to grandchild survival occurring during the critical period of 1-2 years old when infants are still nursing and on the cusp of being weaned (Shanley et al. 2007). This suggests that provisioning of adult daughters to subsidize nursing energy needs may have served as the primary role for postmenopausal women that initially selected for a longer lifespan.

Though many of the specific tenets of these two hypotheses differ, they share one crucial argument: active foraging and food sharing in support of offspring production and viability have imbued humans with the potential for reproductive value at much older ages than expected from theory, or from comparative data on panins. By extension, these hypotheses predict that selection has favored human phenotypes that retain the capacity for somatic maintenance at those older ages. As such, the human postmenopausal period is interpreted as an evolved, species-typical life history stage, as integral to the human life course as adolescence or childhood, and characterized by low rates of intrinsic senescence in physiological systems, at least into the seventh decade of life (Gurven and Kaplan 2007). This life-history interpretation informs the study of menopause and the postmenopausal lifespan from the perspective of evolutionary medicine. Following these evolutionary hypotheses, it seems reasonable to expect that the evolutionary extension of somatic maintenance should foster low rates of chronic and degenerative diseases, and overall good health during the postmenopausal life history period, at least into the seventh decade of life. Given this expectation, it becomes critical to evaluate the potential lifestyle and behavioral patterns among women in industrial society that may predispose them to postmenopausal disease by diverging sharply from conditions under the natural fertility foraging regime that has likely dominated human evolutionary history.

\section{EVOLUTIONARY EXPECTATIONS FOR POSTMENOPAUSAL HEALTH}

In seeking lifestyle factors that might underlie postmenopausal disease risk in industrialized societies, it is important to first examine the prevalence of the same diseases among older women in hunter-gatherer societies. Overwhelmingly, hunter-gatherers without access to medical care appear not to experience the high rate of decline in early postmenopausal somatic maintenance seen in industrialized populations. Degenerative diseases in foraging populations (as far as they can be diagnosed) are extremely rare, accounting for less than $3 \%$ of deaths before age 60 (Howell 1979; Hill and Hurtado 1996; Gurven and Kaplan 2007). Although degenerative diseases become more common as causes of death after age 60, obesity, hypertension, heart attack and stroke are still very much the exception (Eaton et al. 1988; Gurven and Kaplan 2007). Anthropometric work among the Hadza demonstrates that average body fat percentage remains constant at about 19\% in women from age 18-75 (Sherry and Marlowe 2007), in stark contrast to the increase in body fat with age in postmenopausal women from industrialized societies (Heymsfield et al. 1994). Anecdotal and empirical evidence also points to the maintenance of physical vigor in old age in foragers (Blurton Jones et al. 2002; Hawkes et al. 1989; Walker and Hill 2003), including the observation that older Hadza women tend to work longer and perform difficult foraging tasks more frequently than women of reproductive age (Hawkes et al. 1989; Hawkes et al. 1997). These data show that the metabolic syndrome is rare among huntergatherers, likely related to an absence of age-related body composition change and continued physical activity. Maintenance of somatic physiological systems well past menopause appears to be the hunter-gatherer norm, with an absence of the related high mortality rates that would be present in industrialized society without advanced medical treatment (e.g., insulin for diabetes).

The potential cause(s) of postmenopausal health differences between women living in industrialized vs. hunter-gatherer societies must be understood from a biocultural and evolutionary perspective as a consequence of the divergent conditions under which they live. As stated previously, probably the most important physiological change with menopause is the reduction in estrogen levels. This "hyposteroidal" physiological environment is thought to cause disease by undermining the proper functioning of various somatic physiological systems, especially those related to metabolic health. This hypothesis, however, is contrary to expectations if the postmenopausal lifespan indeed represents an evolved life history period. According to Austad (Austad 1997), “... if menopause is 
an adaptive physiological state molded by evolution... then natural selection would presumably have tailored postreproductive physiology to the hyposteroidal state..." [emphasis in the original]. In other words, if selection has promoted the extension of somatic maintenance past menopause, then one would expect postmenopausal physiology to retain functional capacity despite reduced estrogen levels.

Rather than see this necessarily as a contradiction, it is possible that factors other than just a reduction in steroid hormone levels affect the ability of metabolic systems to maintain their operations after menopause. Alternatively, if lifestyle factors elevate estrogen levels during the premenopausal period in women living under industrialized conditions, the magnitude of hormonal change across the menopausal transition may be greater than in women living in subsistence-level societies, with possibly important physiological consequences (Pollard 2008). Given that physiological systems act not in isolation, but interact and affect one another, it seems reasonable that the physiological effects of behavior and experiences during pre-menopausal life could extend into the postmenopausal period. In the same way that it is reasonable to suspect that selection would have molded human postmenopausal physiology to operate under hypersteroidal conditions, it is also reasonable to predict that the environment (both internal and external) under which individual metabolic physiological systems develop and operate across the reproductive lifespan might predispose those systems to function better or worse in the postmenopausal environment. If this is the case, we might then expect the prevailing conditions of hunter-gatherer life to be integral in preparing metabolic physiological systems for operation in the low-estrogen postmenopausal milieu. From this perspective, cultural variation in subsistence practices and reproduction may be particularly important.

The experience of women in industrialized countries differs in a variety of ways from women's lives in modern hunter-gatherer societies, and many of these same differences likely distinguish industrialized life from conditions during the initial evolution of the postmenopausal life history period. For one, decreased infant and childhood mortality may remove biological filters on survival, thereby promoting higher adult disease risk if phenotypes prone to pre-adult mortality also tend to be prone to chronic disease (Hawkes 2010; Forbes 1997). Reproductive history also diverges between women in low-fertility industrialized populations vs. women practicing natural fertility. In the latter, higher birthrates, longer nursing, and more frequent lactational amenorrhea
(Wood 1994) mean fewer lifetime ovulatory cycles and lower exposure to estrogens, possibly related to decreased risk for reproductive cancers (Henderson et al. 1985; Eaton et al. 1994; Bernstein 2002; Yang and Wu 2005; Yang and Jacobsen 2008). The same factors, given their relationship to estrogen levels, could also relate to metabolic function in the low-estrogen, postmenopausal physiological environment (Xue and Michels 2007).

Diets in industrialized societies, too, differ greatly from the seasonally-variable wild plants and animals that constitute hunter-gatherer diets, which generally tend to be higher in fiber and low in fat (Cordain et al. 2000; Cordain et al. 2002; Eaton and Konner 1985; Eaton et al. 1997; Konner and Eaton 2010). Disparities in consumption of fiber, simple carbohydrates, and fat likely relate to higher metabolic disease risk in industrialized populations, partly through effects on estrogen levels and related metabolic processes. Contrary to the estrogendeficiency model of postmenopausal metabolic disease, however, characteristics of the typical hunter-gatherer diet actually tend to decrease estrogen levels. Greater dietary fiber intake, for example, is correlated with lower concentrations of estrogen and estrogen metabolites in the blood (Sowers et al. 2006; Wayne et al. 2008; Gaskins et al. 2012), as are low fat diets (Gencel et al. 2012; Nagata et al. 2005; Turner 2011). In addition to greater estrogen from lowfiber/high-fat diets, women in industrialized societies may add more estrogen to the circulation from consumption of dairy products, in particular from dairy cattle bred to lactate year-round (Davoodi et al. 2013). According to the model of low estrogen as a deficiency disease, a typical low-fat, high-fiber, and dairy-free hunter-gatherer diet should increase risk for metabolic disease vs. a high-fat, low-fiber Western diet. This is, however, demonstrably not the case, and the evolutionary perspective suggests that dietary elevation of circulating estrogen during the premenopausal period may in fact have a carry-over effect on postmenopausal metabolic physiology that increases disease risk.

A fourth factor is the substantial difference in physical activity between hunter-gatherer women, who engage in regular, vigorous physical activity to obtain food, vs. the generally more sedentary women of industrialized societies (Hayes et al. 2005). Low exercise levels result in generalized health problems (Cordain et al. 1997; Eaton and Eaton 2003; Chakravarthy and Booth 2004), but the particular relationship between exercise, estrogen, and metabolic physiology may put inactive postmenopausal women at even greater risk for metabolic and cardiovascular diseases (Major et al. 2005; Torrens et al. 2009). In premenopausal women, higher levels of 
exercise correlate with suppression of estrogen levels (Jasienska et al. 2006), and in extreme cases lead to athletic amenorrhea and interruption of ovulation (Mcardle et al. 2001). Higher overall levels of estrogen compared to men, however, mean that women tend to burn more fat for energy both at rest and during exercise (Tarnopolsky 2008). This metabolic difference fades with menopausal hormone changes (Isacco et al. 2012), possibly making postmenopausal women prone to fat gain. Low activity combined with low estrogen levels after menopause may also limit the body's ability to build cardiovascular and muscular adaptations to exercise (Grounds 1998; Grounds 2002; Harris 2005), potentially blunting the health benefits of exercise interventions in sedentary postmenopausal women. These factors suggest that postmenopausal women are more susceptible to metabolic diseases regardless of exercise levels. Recent work shows, however, that resting energy expenditure, a fundamental indicator of metabolic function, has a dose-response relationship with exercise in postmenopausal women (Froehle et al. 2013). Thus, exercise after menopause appears to have metabolic effects that can compensate for the consequences of lowered estrogen (Spangenburg et al. 2012).

Researchers have only recently begun to focus on how these lifestyle and behavioral factors affect metabolic disease risk and prevalence specifically in the low-estrogen postmenopausal physiological context. The combined evidence provides some interesting leads, though, and points to potentially promising avenues for continued research. A common feature of the reproductive, dietary, and activity differences between women in industrialized societies and women in subsistence-level, natural fertility societies, is their effects on premenopausal estrogen levels. High lifetime fertility and breastfeeding, a diet high in fiber and low in fat, and greater levels of activity all characterize the hunter-gatherer lifestyle, and all have the common effect of suppressing estrogen levels during the reproductive years. The opposite is true of the typical lifestyle in industrialized societies, where women are subject to much higher estrogen exposure over the premenopausal lifespan. The difference may be critical to postmenopausal physiological functioning given the key role of estrogen in metabolism. It is possible that low estrogen levels during the premenopausal period "prime" metabolic systems to function under that hormonal regime, so that after the menopausal reduction in estrogen the body maintains greater capacity to function normally, even in the presence of low circulating estrogen.

In contrast, if the body adapts to high estrogen levels prior to menopause, the magnitude of the menopausal drop in estrogen and subsequent low-estrogen postmenopausal environment may more greatly disrupt metabolic pathways, resulting in higher disease risk without substantial intervention. This hypothesis has already been presented with regard to bone disease (Pollard 2008; Galloway 1997), and may very well also extend to metabolic disease. Additionally, if the degree of hormonal change around the time of menopause is important to postmenopausal metabolic function, then lifestyle interventions that seek to lower estrogen levels need to begin as far before menopause as possible (Spangenburg, Wohlers et al. 2012; Appt and Ethun 2010; DiPietro 2010). Some speculations as to possible areas of non-pharmacological, behavioral modes of prevention are discussed below.

\section{Conclusion}

Overwhelmingly, the evidence from comparative demography and comparative biology contradict the tenets of the medical model of menopause and the postmenopausal lifespan. Rather than being a recent technological development in industrialized societies that extends the lifespan past its evolutionarily intended endpoint, the postmenopausal period is shared broadly across a wide range of human societies living under widely varying nutritional and medical conditions. The shared age at menopause between humans and panins, coupled with greatly reduced mid-life adult mortality rates in the former vs. the latter, also suggest strongly that the postmenopausal lifespan has evolved not by early termination of the reproductive period, but instead by lengthening the lifespan of somatic physiological systems beyond a retained ancestral age range for menopause. In short, multi-decade postmenopausal survival that accounts for roughly one-third of the total lifespan is an evolved, species-defining trait in humans, and should be considered a normal life history phase akin to childhood, adolescence, or reproductive adulthood.

Whereas the postmenopausal lifespan is universally experienced across societies, however, it does not universally represent the initiation of a period of metabolic disease risk and decline. Given evidence that the lifespan has been selected to last past menopause, the low-estrogen deficiency disease model that prevails in Western medicine is flawed. Rather than a period of uncontrolled disruption to metabolic homeostasis, the evolutionary approach proposes that metabolic physiological systems have evolved to maintain sound function after menopause, despite decreased circulating estrogen. Instead of focusing on prescribing estrogen to cure a perceived deficiency, more effective strategies to minimize postmenopausal metabolic disease among women in industrialized 
countries should follow from a better understanding of the conditions under which human physiology largely evolved. Four key areas of continued research can potentially contribute to developing preventive strategies by addressing the effects of lifestyle and behavioral factors on estrogen levels during premenopausal life, their effect on the magnitude of the menopausal reduction in circulating estrogen, and the consequences for metabolic function after menopause. These areas are: 1) the effects of decreased infant and child mortality on adult disease risk; 2) the effects of reproductive patterns on estrogen levels; 3) the effects of diet on body composition and metabolic function in relation to estrogen; and 4) the effects of physical activity on metabolic function, again with regard to estrogen physiology.

First, there are clearly ethical concerns with advocating greater childhood mortality or interfering with individual women's choices about reproduction, contraception, or family planning, and so preventive strategies deriving from the first two areas above are unlikely to be developed (nor should they be, in this author's opinion). Studying the effects of early life experiences on later life physiology, however, as well as genetic predisposition to certain conditions, may be fruitful in identifying women who may be at greater risk of developing metabolic diseases after menopause. Such information would be useful in tailoring preventive exercise and dietary programs early in life so as to maximize postmenopausal health.

Certainly, advocating diets higher in fiber and lower in many kinds of fat, along with greater levels of physical activity is important not only to general health, but also specifically for metabolic health after menopause. Initiating these habits as early as possible in the lifespan may be critical to developing a metabolic adaptation to lower levels of estrogen, which may then prime these physiological systems to maintain function after menopause. There is already some interesting thought in this direction (Pollard 2008; Spangenburg et al. 2012), and continued work in this vein has great promise in reducing the prevalence of midlife metabolic disease among women in industrialized societies. Overall, it is critical to understand menopause in its broader evolutionary and biological context so as to recognize that life past menopause is not a disease, but has likely been an integral part of the lifespan of most women for millennia (Blurton Jones et al. 2002; Caspari and Lee 2004). Using the framework of evolutionary medicine to study menopause offers the opportunity to develop lifelong preventive strategies that ensure postmenopausal health, and that have the potential to change societal, and perhaps more importantly for health, medical perceptions of menopause.

\section{Notes}

1 This paper focuses on "natural menopause," the result of innate physiological processes, as opposed to surgical menopause, which is a consequence of various surgical procedures, including hysterectomy and oophorectomy.

2 National Library of Medicine: http://www.nlm.nih.gov/ medlineplus/menopause.html (May 21, 2013); National Institute on Aging: http://www.nia.nih.gov/health/ publication/menopause (May 21, 2013); Mayo Clinic: http://www.mayoclinic.com/health/menopause/DS00119 (May 21, 2013).

3 National Health and Nutrition Examination Survey, obtained from National Center for Health Statistics, Health Data Interactive, http://www.cdc.gov/nchs/hdi.htm, accessed May 21, 2013.

\section{ACKNOWLEDGEMENTS}

The author thanks Margaret Schoeninger, Jim Moore, Sue Hopkins, Loki Natarajan, Katerina Semendeferi, and two anonymous reviewers for their helpful comments on various incarnations of this manuscript.

\section{REFERENCES}

1. Adekunle, A. O., A. O. Fawole, and M. A. Okunlola

2000 Perceptions and attitudes of Nigerian women about the menopause. J Obstet.Gynaecol. 20(5):525-529.

2. Ames, B. N., R. Cathcart, E. Schwiers, and P. Hochstein

1981 Uric acid provides an antioxidant defense in humans against oxidant- and radical-caused aging and cancer: a hypothesis. Proc.Natl.Acad.Sci.U.S A 78(11):6858-6862.

3. Appt, S. E. and K. F. Ethun

2010 Reproductive aging and risk for chronic disease: Insights from studies of nonhuman primates. Maturitas 67(1):7-14.

4. Atsalis, S. and E. Videan

2009a Reproductive aging in captive and wild common chimpanzees: factors influencing the rate of follicular depletion. Am.J Primatol. 71(4):271-282.

5. Atsalis, S. and E. N. Videan

2009b Functional versus operational menopause: reply to Herndon \& Lacreuse. Am.J Primatol. 71(11):893-894.

6. Austad, S. N.

1997 Postreproductive survival. In Between Zeus and the salmon: the biodemography of longevity. K. W. Wachter and C. E. Finch, eds. Pp. 161-174.Washington, DC: National Academy Press.

7. Ayatollahi, S. M., H. Ghaem, and S. A. Ayatollahi 
2003 Menstrual-reproductive factors and age at natural menopause in Iran. Int.J Gynaecol.Obstet. 80(3):311313.

8. Balan, V. E.

1995 [Epidemiology of the climacteric period in a large city]. Akush.Ginekol.(Mosk)(3):25-28.

9. Barja, G., et al.

1994 Low mitochondrial free radical production per unit $\mathrm{O} 2$ consumption can explain the simultaneous presence of high longevity and high aerobic metabolic rate in birds. Free Radic.Res 21(5):317-327.

10. Beall, C. M.

1983 Ages at menopause and menarche in a high-altitude Himalayan population. Ann.Hum.Biol 10(4):365-370.

11. Bell, F. C. and Miller, M. L.

Life tables for the United States Social Security Area 19002100. Social Security Administration, Office of the Chief Actuary. Actuarial Study No. 120. 2005. Baltimore, MD, Social Security Administration, Office of the Chief Actuary. Actuarial Study.

Ref Type: Report

12. Bellino, F. L. and P. M. Wise 2003 Nonhuman primate models of menopause workshop. Biol Reprod. 68(1):10-18.

13. Bernstein, L.

2002 Epidemiology of endocrine-related risk factors for breast cancer. J Mammary.Gland.Biol Neoplasia. 7(1):315.

14. Bernstein, R. M., K. N. Sterner, and D. E. Wildman

2012 Adrenal androgen production in catarrhine primates and the evolution of adrenarche. American Journal of Physical Anthropology 147(3):389-400.

15. Blevins, J. K., J. E. Coxworth, J. E. Herndon, and K. Hawkes

2013 Brief Communication: Adrenal androgens and aging: female chimpanzees (Pan troglodytes) compared with women. American Journal of Physical Anthropology 151643-648.

16. Bloch, D., C. H. Lockyer, and M. Zachariassen

1993 Age and growth parameters of the long-finned pilot whale off the Faroe Islands. Report of the International Whaling Commission 14(Special Issue):163-207.

17. Blurton Jones, N. G., K. Hawkes, and J. F. O'Connell 2002 Antiquity of postreproductive life: are there modern impacts on hunter-gatherer postreproductive life spans? Am.J Hum Biol 14(2):184-205.

18. Blurton Jones, N. G., K. Hawkes, and J. F. O'Connell 2005 Hadza grandmothers as helpers. In The evolutionary significance of the second half of female life. E. Voland, A. Chasiotis, and W. Schiefenhövel, eds. Pp. 160-176.
Piscatawy, NJ: Rutgers University Press.

19. Boesch, C. and K. Boesch-Achermann

2000 The chimpanzees of the Taï Forest: behavioural ecology and evolution.New York: Oxford University Press.

20. Bribiescas, R. G.

2006 On the evolution, life history, and proximate mechanisms of human male reproductive senescence. Evolutionary Anthropology 15(4):132-141.

21. Bronikowski, A. M., et al.

2002 The aging baboon: comparative demography in a non-human primate. Proc.Natl.Acad.Sci.U.S A 99(14):9591-9595.

22. Burch, P. R. and F. W. Gunz

1967 The distribution of the menopausal age in New Zealand. An exploratory study. N.Z.Med J 66(413):6-10.

23. Campbell, S. E. and M. A. Febbraio

2001 Effect of ovarian hormones on mitochondrial enzyme activity in the fat oxidation pathway of skeletal muscle. American Journal of Physiology-Endocrinology and Metabolism 281(4):E803-E808.

24. Campbell, S. E., et al.

200317 beta-estradiol upregulates the expression of peroxisome proliferator-activated receptor alpha and lipid oxidative genes in skeletal muscle. Journal of Molecular Endocrinology 31(1):37-45.

25. Carda, S. N., et al.

1998 The menopausal age, related factors and climacteric symptoms in Turkish women. Maturitas 3037-40.

26. Carey, J. R. and D. S. Judge

2001 Life span extension in humans is self-reinforcing: A general theory of longevity. Population and Development Review 27(3):411-+.

27. Caro, T. M., et al.

1995 Termination of Reproduction in Nonhuman and Human Female Primates. International Journal of Primatology 16(2):205-220.

28. Carr, M. C.

2003 The emergence of the metabolic syndrome with menopause. Journal of Clinical Endocrinology and Metabolism 88(6):2404-2411.

29. Caspari, R. and S. H. Lee

2004 Older age becomes common late in human evolution. Proc.Natl.Acad Sci U.S A 101(30):10895-10900.

30. Castelo-Branco, C., et al.

2006 Age at menopause in Latin America. Menopause 13(4):706-712.

31. Castelo-Branco, C., et al.

2005 Menopausal transition in Movima women, a Bolivian Native-American. Maturitas 51(4):380-385. 
32. Centers for Disease Control and Prevention (CDC).

National Center for Health Statistics (NCHS). National Health and Nutrition Examination Survey Data. Hyattsville, MD: U.S. Department of Health and Human Services, Centers for Disease Control and Prevention, 2005-2008, http://www.cdc.gov/nchs/hdi. htm. 2011.

Ref Type: Generic

33. Chakravarthy, M. V. and F. W. Booth

2004 Eating, exercise, and "thrifty" genotypes: connecting the dots toward an evolutionary understanding of modern chronic diseases. Journal of Applied Physiology 96(1):3-10.

34. Charbonneau, D. H.

2010 Manufacturing Menopause: An Analysis Of The Portrayal Of Menopause And Information Content On Pharmaceutical Web Sites. PhD dissertation, Dissertation, Wayne State University.

35. Charlesworth, B.

1994 Evolution in age-structured populations.2 edition. Cambridge, UK: Cambridge University Press.

36. Chim, H., et al.

2002 The prevalence of menopausal symptoms in a community in Singapore. Maturitas 41(4):275-282.

37. Chow, S. N., C. C. Huang, and Y. T. Lee

1997 Demographic characteristics and medical aspects of menopausal women in Taiwan. J Formos.Med Assoc. 96(10):806-811.

38. Cimons, $\mathrm{M}$.

2008 The medicalization of menopause: Framing media messages in the twentieth century. PhD dissertation, Dissertation, University of Maryland.

39. Clancy, K. B. H.

2009 Reproductive Ecology and the Endometrium: Physiology, Variation, and New Directions. Yearbook of Physical Anthropology, Vol 52 52137-154.

40. Cohen, A. A.

2004 Female post-reproductive lifespan: a general mammalian trait. Biol Rev.Camb.Philos.Soc. 79(4):733750.

41. Cordain, L., et al.

2002 The paradoxical nature of hunter-gatherer diets: meat-based, yet non-atherogenic. European Journal of Clinical Nutrition 56S42-S52.

42. Cordain, L., R. W. Gotshall, and S. B. Eaton

1997 Evolutionary aspects of exercise. Nutrition and Fitness: Evolutionary Aspects, Children'S Health, Programs and Policies 8149-60.

43. Cordain, L., et al.
2000 Plant-animal subsistence ratios and macronutrient energy estimations in worldwide hunter-gatherer diets. American Journal of Clinical Nutrition 71(3):682-692.

44. Cortopassi, G. A. and E. Wang

1996 There is substantial agreement among interspecies estimates of DNA repair activity. Mechanisms of Ageing and Development 91(3):211-218.

45. Cramer, D. W., H. J. Xu, and B. L. Harlow

1995 Family History As A Predictor of Early Menopause. Fertility and Sterility 64(4):740-745.

46. Cresswell, J. L., et al.

1997 Is the age of menopause determined in-utero? Early Hum Dev. 49(2):143-148.

47. Crews, D. E.

2003 Human Senescence: Evolutionary and Biocultural Perspectives.Cambridge, UK: Cambridge University Press.

48. Crittenden, A. N., et al.

2009 Foraging strategies and diet composition of Hadza children. American Journal of Physical Anthropology112.

49. Cutler, D. and G. Miller

2005 The role of public health improvements in health advances: The twentieth-century United States. Demography 42(1):1-22.

50. Dahlgren, E., et al.

1992 Women with Polycystic-Ovary-Syndrome Wedge Resected in 1956 to 1965 - A Long-Term FollowUp Focusing on Natural-History and Circulating Hormones. Fertility and Sterility 57(3):505-513.

51. Davoodi, H., S. Esmaeili, and A. M. Mortazavian

2013 Effects of Milk and Milk Products Consumption on Cancer: A Review. Comprehensive Reviews in Food Science and Food Safety 12249-264.

52. de Bruin, J. P., et al.

2001 The role of genetic factors in age at natural menopause. Human Reproduction 16(9):2014-2018.

53. den Tonkelaar, I., E. R. T. Velde, and C. W. N. Looman 1998 Menstrual cycle length preceding menopause in relation to age at menopause. Maturitas 29(2):115-123.

54. DiPietro, L.

2010 Exercise training and fat metabolism after menopause: implications for improved metabolic flexibility in aging. Journal of Applied Physiology 109(6):1569-1570.

55. Eaton, S. B. and S. B. Eaton

2003 An evolutionary perspective on human physical activity: implications for health. Comparative Biochemistry and Physiology A-Molecular \& 
Integrative Physiology 136(1):153-159.

56. Eaton, S. B., S. B. Eaton, and M. J. Konner

1997 Paleolithic nutrition revisited: A twelve-year retrospective on its nature and implications. European Journal of Clinical Nutrition 51(4):207-216.

57. Eaton, S. B. and M. Konner

1985 Paleolithic Nutrition - A Consideration of Its Nature and Current Implications. New England Journal of Medicine 312(5):283-289.

58. Eaton, S. B., M. Konner, and M. Shostak

1988 Stone Agers in the Fast Lane - Chronic Degenerative Diseases in Evolutionary Perspective. American Journal of Medicine 84(4):739-749.

59. Eaton, S. B., et al.

1994 Womens Reproductive Cancers in Evolutionary Context. Quarterly Review of Biology 69(3):353-367.

60. Elias, S. G., et al.

2003 Caloric restriction reduces age at menopause: the effect of the 1944-1945 Dutch famine. Menopause-the Journal of the North American Menopause Society 10(5):399-405.

61. Ellison, P. T.

2010 Life historical perspectives on human reproductive aging. Reproductive Aging 120411-20.

62. Emery, Thompson M., et al.

2007 Aging and fertility patterns in wild chimpanzees provide insights into the evolution of menopause. Curr.Biol 17(24):2150-2156.

63. Enns, Deborah L. and Peter M. Tiidus

2010 The Influence of Estrogen on Skeletal Muscle Sex Matters. Sports Medicine 40(1):41-58.

64. Ettinger, B., et al.

2012 Evolution of postmenopausal hormone therapy between 2002 and 2009. Menopause-the Journal of the North American Menopause Society 19(6):610-615.

65. Faddy, M. J., et al.

1992 Accelerated Disappearance of Ovarian Follicles in Midlife - Implications for Forecasting Menopause. Human Reproduction 7(10):1342-1346.

66. Fedigan, L. M. and M. S. M. Pavelka

2006 Reproductive cessation in female primates: comparisons of Japanese macaques and humans. In Primates in perspective. C. Campbell, et al., eds. Pp. 437-447.Oxford: Oxford University Press.

67. Finch, C. E.

1990 Longevity, senescence and the genome.Chicago: University of Chicago Press.

68. Finch, C. E. and T. B. L. Kirkwood
2000 Chance, development, and aging.New York: Oxford University Press.

69. Finch, C. E. and C. B. Stanford

2004 Meat-adaptive genes and the evolution of slower aging in humans. Quarterly Review of Biology 79(1):350.

70. Flint, $M$

1974 Menarche and menopause of Rajput women. PhD dissertation, Dissertation, City University of New York.

71. Foote, A. D.

2008 Mortality rate acceleration and post-reproductive lifespan in matrilineal whale species. Biol Lett. 4(2):189191.

72. Forbes, L. S.

1997 The evolutionary biology of spontaneous abortion in humans. Trends in Ecology \& Evolution 12(11):446450.

73. Fox, M., et al.

2010 Grandma plays favourites: X-chromosome relatedness and sex-specific childhood mortality. Proceedings of the Royal Society B-Biological Sciences 277(1681):567-573.

74. Friedman, T. B., G. E. Polanco, J. C. Appold, and Mayle J.E. 1995 On the loss of uricolytic activity during primate evolution-I. Silencing of urate oxidase in a hominoid ancestor. Comparative Biochemistry and Physiology B 81B653-659.

75. Froehle, A. W., S. R. Hopkins, L. Natarajan, and M. J. Schoeninger

2013 Moderate-to-high levels of exercise are associated with higher resting energy expenditure in communitydwelling postmenopausal women. Applied Physiology, Nutirition and Metabolism In press.

76. Froehle, A. W. and M. J. Schoeninger

2006Intraspecies variation in BMR doesnot affectestimates of early hominin total daily energy expenditure. American Journal of Physical Anthropology 131(4):552559.

77. Fuchs, M. and C. Paskarbeit

1976 [Age of menopause in the DDR]. Sante Publique (Bucur.) 19(2):193-200.

78. Fukuhara, R., T. Tezuka, and T. Kageyama

2002 Structure, molecular evolution, and gene expression of primate superoxide dismutases. Gene 296(1-2):99109.

79. Galloway, A.

1997 The cost of reproduction and the evolution of postmenopausal osteoporosis. In The evolving female: a life-history perspective. M. E. Morbeck, A. Galloway, 
and A. L. Zihlman, eds. Pp. 132-146.Princeton, NJ: Princeton University Press.

80. Gammelgaard, A.

2000 Evolutionary biology and the concept of disease. Med Health Care Philos. 3(2):109-116.

81. Garrido-Latorre, F., E. C. Lazcano-Ponce, L. Lopez-Carrillo, and M. Hernandez-Avila

1996 Age of natural menopause among women in Mexico

City. Int.J Gynaecol.Obstet. 53(2):159-166.

82. Gaskins, A. J., S. L. Mumford, J. Wactawski-Wende, and E. F. Schisterman

2012 Effect of daily fiber intake on luteinizing hormone levels in reproductive-aged women. Eur.J Nutr 51(2):249-253.

83. Gavrilov, L. A. and N. S. Gavrilova

2006 Reliability theory of aging and longevity. In Handbook of the biology of aging. E. J. Masoro and S. N. Austad, eds. Pp. 3-42.San Diego: Elsevier Academic Press.

84. Gencel, V. B., M. M. Benjamin, S. N. Bahou, and R. A. Khalil 2012 Vascular effects of phytoestrogens and alternative menopausal hormone therapy in cardiovascular disease. Mini.Rev Med Chem. 12(2):149-174.

85. Gluckman, P. D. and A. S. Beedle

2007 Migrating ovaries: early life influences on later gonadal function. PLoS Med 4(5):e190.

86. Gluckman, P. D., M. A. Hanson, and H. G. Spencer 2005 Predictive adaptive responses and human evolution. Trends Ecol.Evol. 20(10):527-533.

87. Gonzales, G. F., A. Villena, and D. DeLaCruz

1997 Age of natural menopause among women in Lima City, Peru. International Journal of Gynecology \& Obstetrics 57(1):69-72.

88. Goodman, M., et al.

1998 Toward a phylogenetic classification of Primates based on DNA evidence complemented by fossil evidence. Mol.Phylogenet.Evol. 9(3):585-598.

89. Gould, K. G., M. Flint, and C. E. Graham

1981 Chimpanzee reproductive senescence: a possible model for evolution of the menopause. Maturitas 3(2):157-166.

90. Graham, C. E.

1979 Reproductive function in aged female chimpanzees. Am.J Phys Anthropol. 50(3):291-300.

91. Gray, R. H.

1976 The menopause-epidemiological and demographic considerations. In The menopause: a guide to current research and practice. R. J. Beard, ed. Pp. 25-40. Baltimore: University Park Press.
92. Greenspan, F. S. and D. G. Gardner

2004 Basic \& Clinical Endocrinology.7 edition.New York: McGraw Hill.

93. Greer, W., A. L. Sandridge, and R. S. Chehabeddine 2003 The frequency distribution of age at natural menopause among Saudi Arabian women. Maturitas 46(4):263-272.

94. Grounds, M. D.

1998 Age-associated changes in the response of skeletal muscle cells to exercise and regeneration. Ann N.Y.Acad Sci 85478-91.

95. Grounds, M. D.

2002 Reasons for the degeneration of ageing skeletal muscle: a central role for IGF-1 signalling. Biogerontology. 3(1-2):19-24.

96. Gurven, M. and H. S. Kaplan

2007 Longevity among hunter-gatherers: a cross-cultural examination. Population and Development Review 33321-365.

97. Gurven, M. and R. Walker

2006 Energetic demand of multiple dependents and the evolution of slow human growth. Proc.Biol Sci. 273(1588):835-841.

98. Hagstad, A.

1988 Gynecology and sexuality in middle-aged women. Women \& Health 1357-80.

99. Haines, M. R.

Estimated life tables for the United States, 1850-1900. 59. 1994. Cambridge, MA, National Bureau of Economic Research. Historical Paper Series.

Ref Type: Report

100. Hamilton, W. D.

1966 The moulding of senescence by natural selection. J Theor.Biol 12(1):12-45.

101. Hansen, K. R., et al.

2008 A new model of reproductive aging: the decline in ovarian non-growing follicle number from birth to menopause. Hum.Reprod. 23(3):699-708.

102. Hardy, R. and D. Kuh

2002 Does early growth influence timing of the menopause? Evidence from a British birth cohort. Hum Reprod. 17(9):2474-2479.

103. Hardy, R. and D. Kuh

2005 Social and environmental conditions across the life course and age at menopause in a British birth cohort study. BJOG. 112(3):346-354.

104. HARMAN, D.

1956 Aging: a theory based on free radical and radiation chemistry. J Gerontol. 11(3):298-300. 
105. Harris, B. A.

2005 The influence of endurance and resistance exercise on muscle capillarization in the elderly: a review. Acta Physiol Scand. 185(2):89-97.

106. Hawkes, K.

2003 Grandmothers and the evolution of human longevity. Am.J Hum Biol 15(3):380-400.

107. Hawkes, K.

2010 How grandmother effects plus individual variation in frailty shape fertility and mortality: guidance from human-chimpanzee comparisons. Proc Natl Acad Sci, USA 107(Suppl. 2):8977-8984.

108. Hawkes, K., J. F. O'Connell, and N. G. Blurton Jones 1989 Hardworking Hadza grandmothers. In Comparative Socioecolgy: The behavioral ecology of humans and other mammals. V. Standen and R. A. Foley, eds. Pp. 341-366.London: Blackwell Scientific Publications.

109. Hawkes, K., J. F. O'Connell, and N. G. Blurton Jones

1995 Hadza children's foraging: juvenile dependency, social arrangements, and mobility among huntergatherers. Current Anthropology 36688-700.

110. Hawkes, K., J. F. O'Connell, and N. G. Blurton Jones

1997 Hadza women's time allocation, offspring provisioning, and the evolution of long postmenopausal life spans. Curr Anthropol 38(4):551-577.

111. Hawkes, K., et al.

1998 Grandmothering, menopause, and the evolution of human life histories. Proc.Natl.Acad Sci U.S A 95(3):1336-1339.

112. Hawkes, K. and K. R. Smith

2010 Do women stop early? Similarities in fertility decline in humans and chimpanzees. Ann N.Y.Acad Sci 12044353.

113. Hayes, M., et al.

2005 Low physical activity levels of modern Homo sapiens among free-ranging mammals. International Journal of Obesity 29(1):151-156.

114. Henderson, B. E., et al.

1985 Do Regular Ovulatory Cycles Increase BreastCancer Risk. Cancer 56(5):1206-1208.

115. Herndon, J. G. and A. Lacreuse

2009 "Reproductive aging in captive and wild common chimpanzees: factors influencing the rate of follicular depletion," by S. Atsalis and E. Videan, American Journal of Primatology 71, 271-282 (2009). Am.J Primatol. 71(11):891-892.

116. Heymsfield, S. B., et al.

1994 Menopausal Changes in Body-Composition and Energy-Expenditure. Experimental Gerontology 29(3-
4):377-389.

117. Hill, K., et al.

2001 Mortality rates among wild chimpanzees. J Hum Evol. 40(5):437-450.

118. Hill, K. and A. M. Hurtado

1996 Ache life history: the ecology and demography of a

foraging people.New York: Aldine de Gruyter.

119. Howell, N.

1979 Demography of the Dobe !Kung.New York: Academic Press.

120. Hunt, E. E., Jr. and N. W. Newcomer

1984 The timing and variability of menarche, cumulative fertility and menopause: a symmetrical and parsimonious bioassay model. Hum.Biol 56(1):47-62.

121. Isacco, L., P. Duche, and N. Boisseau

2012 Influence of Hormonal Status on Substrate Utilization at Rest and during Exercise in the Female Population. Sports Medicine 42(4):327-342.

122. Ismael, N. N.

1994 A study on the menopause in Malaysia. Maturitas 19(3):205-209.

123. Jasienska, G., et al.

2006 Habitual physical activity and estradiol levels in women of reproductive age. Eur.J Cancer Prev. 15(5):439-445.

124. Johnson, B. D., et al.

2004 Determination of menopausal status in women: the NHLBI-sponsored Women's Ischemia Syndrome Evaluation (WISE) Study. J Womens Health (Larchmt.) 13(8):872-887.

125. Jones, K. P., et al.

2007 Depletion of ovarian follicles with age in chimpanzees: similarities to humans. Biol Reprod. 77(2):247-251.

126. Jurke, M. H., L. R. Hagey, S. Jurke, and N. M. Czekala 2000 Monitoring hormones in urine and feces of captive bonobos (Pan paniscus). Primates 41(3):311-319.

127. Kaplan, H. S. and M. Gurven

2005 The Natural History of Human Food Sharing and Cooperation: A Review and a New Multi-Individual Approach to the Negotiation of Norms . In Moral sentiments and material interests: the foundaitons of cooperation in economic life. H. Gintis, S. Bowles, R. Boyd, and E. Fehr, eds. Pp. 75-114.Cambridge, MA: MIT Press.

128. Kapoor, A. K. and S. Kapoor

1986 The effects of high altitude on age at menarche and menopause. Int.J Biometeorol. 30(1):21-26.

129. Karim, A., A. K. Chowdhury, and M. Kabir 
1985 Nutritional status and age at secondary sterility in rural Bangladesh. J Biosoc.Sci. 17(4):497-502.

130. Kasuya, T. and H. Marsh

1984 Life history and reproductive biology of the shortfinned pilot whale, Globicephala macrorhynchus, off the Pacific Coast of Japan. Report of the International Whaling Commission 6(Special Issue):259-310.

131. Kato, I., et al.

1998 Prospective study of factors influencing the onset of natural menopause. Journal of Clinical Epidemiology 51(12):1271-1276.

132. Kaufert, P. A., P. Gilbert, and R. Tate

1987 Defining Menopausal Status - the Impact of Longitudinal Data. Maturitas 9(3):217-226.

133. Kelly, R. L.

1995 The Foraging Spectrum.Washington, DC: Smithsonian Institution.

134. Kemnitz, J. W., et al.

2000 Serum dehydroepiandrosterone sulfate concentrations across the life span of laboratory-housed rhesus monkeys. Journal of Medical Primatology 29(5):330-337.

135. Kirkwood, T. B. L.

1977 Evolution of Aging. Nature 270(5635):301-304.

136. Kirkwood, T. B. L.

1980 Error Propagation in Intracellular InformationTransfer. Journal of Theoretical Biology 82(3):363-382.

137. Kirkwood, T. B. L. and R. Holliday

1979 Evolution of Aging and Longevity. Proceedings of the Royal Society B-Biological Sciences 205(1161):531546 .

138. Kirkwood, T. B. L. and D. P. Shanley

2010 The connections between general and reproductive senescence and the evolutionary basis of menopause.

139. Konner, M. and S. B. Eaton

2010 Paleolithic Nutrition Twenty-Five Years Later. Nutrition in Clinical Practice 25(6):594-602.

140. Kono, S., Y. Sunagawa, H. Higa, and H. Sunagawa

1990 Age of menopause in Japanese women: trends and recent changes. Maturitas 12(1):43-49.

141. Kriplani, A. and K. Banerjee

2005 An overview of age of onset of menopause in northern India. Maturitas 52(3-4):199-204.

142. Ku, H. H. and R. S. Sohal

1993 Comparison of Mitochondrial Prooxidant Generation and Antioxidant Defenses Between Rat and Pigeon - Possible Basis of Variation in Longevity and Metabolic Potential. Mechanisms of Ageing and
Development 72(1):67-76.

143. $\mathrm{Ku}, \mathrm{S}$. Y., et al.

2004 Regional differences in age at menopause between

Korean-Korean and Korean-Chinese. Menopause-the Journal of the North American Menopause Society 11(5):569-574.

144. Kwawukume, E. Y., T. S. Ghosh, and J. B. Wilson 1993 Menopausal age of Ghanaian women. Int.J Gynaecol. Obstet. 40(2):151-155.

145. Lacreuse, A., et al.

2008 Menstrual cycles continue into advanced old age in the common chimpanzee (Pan troglodytes). Biology of Reproduction 79(3):407-412.

146. Lahdenpera, M., et al.

2004 Fitness benefits of prolonged post-reproductive lifespan in women. Nature 428(6979):178-181.

147. Lahdenpera, M., A. F. Russell, M. Tremblay, and V. Lummaa 2011 Selection on Menopause in Two Premodern Human Populations: No Evidence for the Mother Hypothesis. Evolution 65(2):476-489.

148. Lane, M. A., D. K. Ingram, S. S. Ball, and G. S. Roth 1997 Dehydroepiandrosterone sulfate: A biomarker of primate aging slowed by calorie restriction. Journal of Clinical Endocrinology \& Metabolism 82(7):2093-2096.

149. Lee, R.

2008 Sociality, selection, and survival: Simulated evolution of mortality with intergenerational transfers and food sharing. Proceedings of the National Academy of Sciences of the United States of America 105(20):7124-7128.

150. Lee, R. D.

2003 Rethinking the evolutionary theory of aging: Transfers, not births, shape social species. Proceedings of the National Academy of Sciences of the United States of America 100(16):9637-9642.

151. Leidy, L. E., L. R. Godfrey, and M. R. Sutherland 1998 Is follicular atresia biphasic? Fertility and Sterility 70(5):851-859.

152. Luoto, R., J. Kaprio, and A. Uutela

1994 Age at natural menopause and sociodemographic status in Finland. Am.J Epidemiol. 139(1):64-76.

153. Magursky, V., M. Mesko, and L. Sokolik

1975 Age at the menopause and onset of the climacteric in women of Martin District, Czechoslovkia. Statistical survey and some biological and social correlations. Int.J Fertil. 20(1):17-23.

154. Major, G. C., et al.

2005 Energy expenditure from physical activity and the metabolic risk profile at menopause. Medicine and 
Science in Sports and Exercise 37(2):204-212.

155. Marnocha, S. K., M. Bergstrom, and L. F. Dempsey

2011 The lived experience of perimenopause and menopause. Contemporary Nurse 37(2):229-240.

156. Marsh, $\mathrm{H}$. and T. Kasuya

1984 Ovarian changes in the short-finned pilot whale, Globicephela macrorhyncus. Report of the International Whaling Commission 6(Special Issue):311-335.

157. Marsh, H. and T. Kasuya

1986 Evidence for reproductive senescence in female cetaceans. Report of the International Whaling Commission 8(Special Issue):57-74.

158. Martin, A. R. and P. Rothery

1993 Reproductive parameters of female long-finned pilot whales (Globicephlea melas) around the Faroe Islands. Report of the International Whaling Commission 14(Special Issue):263-304.

159. Mayer, P. J.

1981 Evolution of menopause: theoretical considerations and empirical conclusions. Am.J Phys.Anthropol. 54250.

160. Mayer, P. J.

1982 Evolutionary advantage of menopause. Hum Ecol 10(4):477-494.

161. Mcardle, W. D., F. I. Katch, and A. L. Katch

2001 Exercise Physiology.5th edition.Philadelphia: Lippincott Williams \& Wilkins.

162. McAuliffe, $\mathrm{K}$. and $\mathrm{H}$. Whitehead

2005 Eusociality, menopause and information in matrilineal whales. Trends in Ecology \& Evolution 20(12):650.

163. McKinlay, S. M., N. L. Bifano, and J. B. McKinlay

1985 Smoking and age at menopause in women. Ann. Intern Med 103(3):350-356.

164. Medawar, P. B.

1952 An Unsolved Problem of Biology.London: H.K. Lewis.

165. Meyer, V. F.

2001 The medicalization of menopause: Critique and consequences. International Journal of Health Services 31(4):769-792.

166. Meyer, V. F.

2003 Medicalized menopause, U.S. style. Health Care for Women International 24822-830.

167. Mishra, G., R. Hardy, and D. Kuh

2007 Are the effects of risk factors for timing of menopause modified by age? Results from a British birth cohort study. Menopause. 14(4):717-724.
168. Mishra, G. D., R. Cooper, and D. Kuh

2010 A life course approach to reproductive health:

Theory and methods. Maturitas 65(2):92-97.

169. Mohammad, K., S. M. S. Hashemi, and F. K. A. Farahani

2004 Age at natural menopause in Iran. Maturitas 49(4):321-326.

170. Morabia, A., et al.

1996 Reproductive characteristics of a population of urban Swiss women. Acta Obstet.Gynecol.Scand. 75(9):838-842.

171. Murabito, J. M., et al.

2005 Heritability of age at natural menopause in the Framingham Heart Study. Journal of Clinical Endocrinology \& Metabolism 90(6):3427-3430.

172. Nagata, C., et al.

2005 Fat intake is associated with serum estrogen and androgen concentrations in postmenopausal Japanese women. Journal of Nutrition 135(12):2862-2865.

173. Narod, S. A.

2011 Hormone replacement therapy and the risk of breast cancer. Nat.Rev Clin Oncol. 8(11):669-676.

174. Nedergaard, A., K. Henriksen, M. A. Karsdal, and C. Christiansen

2013 Menopause, estrogens and frailty. Gynecological Endocrinology 29(5):418-423.

175. Nesse, R. M. and G. C. Williams

1994 Why we get sick: the new science of Dariwnian medicine.New York: Times Books.

176. O'Connell, J. F., K. Hawkes, and N. G. Blurton Jones

1999 Grandmothering and the evolution of homo erectus. J Hum Evol. 36(5):461-485.

177. O'Connor, K. A., D. J. Holman, and J. W. Wood

1998 Declining fecundity and ovarian ageing in natural fertility populations. Maturitas 30(2):127-136.

178. Oda, M., Y. Satta, O. Takenaka, and N. Takahata

2002 Loss of urate oxidase activity in hominoids and its evolutionary implications. Molecular Biology and Evolution 19(5):640-653.

179. Okonofua, F. E., A. Lawal, and J. K. Bamgbose 1990 Features of Menopause and Menopausal Age in Nigerian Women. International Journal of Gynecology \& Obstetrics 31(4):341-345.

180. Olesiuk, P. F., M. A. Bigg, and G. M. Ellis 1990 Life history and population dynamics of resident killer whales (Orcinus orca) in the coastal waters of British Columbia and Washington State. Report of the International Whaling Commission 12(Special Issue):209-243. 
181. Orgel, L. E.

1963 Maintenance of Accuracy of Protein Synthesis and

Tis Relevance to Ageing. Proceedings of the National Academy of Sciences of the United States of America 49(4):517-\&.

182. Orgel, L. E.

1970 Correction. Proceedings of the National Academy of Sciences of the United States of America 67(3):1476-\&.

183. Packer, C., M. Tatar, and A. Collins

1998 Reproductive cessation in female mammals. Nature 392(6678):807-811.

184. Panter-Brick, C.

2002 Sexual division of labor: Energetic and evolutionary scenarios. American Journal of Human Biology 14(5):627-640.

185. Panter-Brick, C., Layton, R. H., and Rowley-Conwy, P.

Hunter-gatherers: an interdisciplinary perspective. 2001. Cambridge, UK, Cambridge University Press.

Ref Type: Edited Book

186. Pavelka, M. S. M. and L. M. Fedigan

1999 Reproductive termination in female Japanese monkeys: A comparative life history perspective. American Journal of Physical Anthropology 109(4):455464.

187. Peccei, J. S.

1995a A hypothesis for the origin and evolution of menopause. Maturitas 21(2):83-89.

188. Peccei, J. S.

1995b The origin and evolution of menopause: the altriciality-lifespan hypothesis. Ethology and Sociobiology 16425-449.

189. Peccei, J. S.

1999 First estimates of heritability in the age of menopause. Curr Anthropol 40(4):553-558.

190. Peccei, J. S.

2001a A critique of the grandmother hypotheses: Old and new. American Journal of Human Biology 13(4):434452.

191. Peccei, J. S.

2001b Menopause: Adaptation or epiphenomenon? Evolutionary Anthropology 10(2):43-57.

192. Peccei, J. S.

2005 Menopause. Adaptation and epiphenomenon. In The evolutionary significance of the second half of female life. E. Voland, A. Chasiotis, and W. Schiefenhövel, eds. Pp. 38-58.Piscataway, NJ: Rutgers University Press.

193. Pollard, T. M.

2008 Western diseases: an evolutionary perspective.New York: Cambridge University Press.
194. Puschmann, W. and E. Federer

2008 Ein neuer fertilitätsnachweis bei einer hoch betagten schimpansin und anmerkungen zum höchstalter von Pan troglodytes. Zoologische Garten 77182-185.

195. Ramoso-Jalbuena, J.

1994 Climacteric Filipino women: a preliminary survey in the Philippines. Maturitas 19(3):183-190.

196. Randolph, J. F., et al.

2011 Change in Follicle-Stimulating Hormone and Estradiol Across the Menopausal Transition: Effect of Age at the Final Menstrual Period. Journal of Clinical Endocrinology \& Metabolism 96(3):746-754.

197. Reynolds, R. F. and C. M. Obermeyer

2001 Age at natural menopause in Beirut, Lebanon: the role of reproductive and lifestyle factors. Ann.Hum. Biol 28(1):21-29.

198. Reynolds, R. F. and C. M. Obermeyer

2003 Correlates of the age at natural menopause in Morocco. Annals of Human Biology 30(1):97-108.

199. Rizk, D. E., et al.

1998 The age and symptomatology of natural menopause among United Arab Emirates women. Maturitas 29(3):197-202.

200. Roof, K. A., et al.

2005 Maternal age, parity, and reproductive outcome in captive chimpanzees (Pan troglodytes). American Journal of Primatology 67(2):199-207.

201. Rossouw, J. E., et al.

2002 Risks and benefits of estrogen plus progestin in healthy postmenopausal women: principal results From the Women's Health Initiative randomized controlled trial. JAMA 288(3):321-333.

202. Roth, G. S., et al.

2002 Biomarkers of caloric restriction may predict longevity in humans. Science 297(5582):811.

203. Samil, R. S. and S. D. Wishnuwardhani

1994 Health of Indonesian women city-dwellers of perimenopausal age. Maturitas 19(3):191-197.

204. Scragg, R. F. R.

Menopause and reproductive span in rural Nuigini. Proceedings of the Ninth Annual Symposium of the Medical Society of Papua New Guinea . 1973.

Ref Type: Conference Proceeding

205. Sear, R., R. Mace, and I. A. McGregor

2000 Maternal grandmothers improve nutritional status and survival of children in rural Gambia. Proc.Biol Sci 267(1453):1641-1647.

206. Sear, R., F. Steele, A. A. McGregor, and R. Mace 2002 The effects of kin on child mortality in rural Gambia. 
Demography 39(1):43-63.

207. Shanley, D. P. and T. B. L. Kirkwood

2001 Evolution of the human menopause. Bioessays 23(3):282-287.

208. Shanley, D. P., R. Sear, R. Mace, and T. B. L. Kirkwood 2007 Testing evolutionary theories of menopause. Proceedings of the Royal Society B-Biological Sciences 274(1628):2943-2949.

209. Shapiro, $S$.

2004 The Million Women Study: potential biases do not allow uncritical acceptance of the data. Climacteric 7(1):3-7.

210. Sherry, D. S. and F. W. Marlowe

2007 Anthropometric data indicate nutritional homogeneity in Hadza foragers of Tanzania. Am.J Hum Biol 19(1):107-118.

211. Sloboda, D. M., M. Hickey, and R. Hart

2011 Reproduction in females: the role of the early life environment. Human Reproduction Update 17(2):210227.

212. Snieder, H., A. J. MacGregor, and T. D. Spector

1998 Genes control the cessation of a woman's reproductive life: a twin study of hysterectomy and age at menopause. J Clin.Endocrinol.Metab 83(6):18751880.

213. Soberon, J., J. J. Calderon, and J. W. Goldzieh

1966 Relation of Parity to Age at Menopause. American Journal of Obstetrics and Gynecology 96(1):96-\&.

214. Sousa, A. O.

2003 Simulation of reproductive risk and emergence of female reproductive cessation. Physica A-Statistical Mechanics and Its Applications 326(1-2):233-240.

215. Sowers, M. R., et al.

2006 Selected diet and lifestyle factors are associated with estrogen metabolites in a multiracial/ethnic population of women. Journal of Nutrition 136(6):1588-1595.

216. Sowers, M. R., et al.

2008 Estradiol rates of change in relation to the final menstrual period in a population-based cohort of women. Journal of Clinical Endocrinology \& Metabolism 93(10):3847-3852.

217. Spangenburg, E. E., P. C. Geiger, L. A. Leinwand, and D. A. Lowe

2012 Regulation of Physiological and Metabolic Function of Muscle by Female Sex Steroids. Medicine and Science in Sports and Exercise 44(9):1653-1662.

218. Spangenburg, E. E., L. M. Wohlers, and A. P. Valencia 2012 Metabolic Dysfunction Under Reduced Estrogen Levels: Looking to Exercise for Prevention. Exercise and Sport Sciences Reviews 40(4):195-203.

219. Stanford, J. L., et al.

1987 Factors Influencing the Age at Natural Menopause.

Journal of Chronic Diseases 40(11):995-1002.

220. Sugiyama, M. G. and L. B. Agellon

2012 Sex differences in lipid metabolism and metabolic disease risk. Biochem.Cell Biol 90(2):124-141.

221. Tanko, L. B. and C. Christiansen

2006 Adipose tissue, insulin resistance and low-grade inflammation: implications for atherogenesis and the cardiovascular harm of estrogen plus progestogen therapy. Climacteric 9(3):169-180.

222. Tarnopolsky, M. A.

2008 Sex differences in exercise metabolism and the role of 17-beta estradiol. Medicine and Science in Sports and Exercise 40(4):648-654.

223. Tarou, L. R., et al.

2002 The behavior of aged great apes. In Aging in nonhuman primates. J. M. Erwin and P. R. Hof, eds. Pp. 209-231. Interdisciplinary Topics in Gerontology SeriesBasel: Karger.

224. te Velde, E. R. and P. L. Pearson

2002 The variability of female reproductive ageing. Human Reproduction Update 8141-154.

225. Thomas, F., et al.

2001 International variability of ages at menarche and menopause: patterns and main determinants. Hum Biol 73(2):271-290.

226. Tolmasoff, J. M., T. Ono, and R. G. Cutler

1980 Superoxide-Dismutase - Correlation with LifeSpan and Specific Metabolic-Rate in Primate Species. Proceedings of the National Academy of Sciences of the United States of America-Biological Sciences 77(5):2777-2781.

227. Tom, S. E., et al.

2010 Fetal environment and early age at natural menopause in a British birth cohort study. Hum Reprod. 25(3):791-798.

228. Torgerson, D. J., A. Avenell, I. T. Russell, and D. M. Reid

1994 Factors Associated with Onset of Menopause in Women Aged 45-49. Maturitas 19(2):83-92.

229. Torgerson, D. J., R. E. Thomas, M. K. Campbell, and D. M. Reid

1997 Alcohol consumption and age of maternal menopause are associated with menopause onset. Maturitas 26(1):21-25.

230. Torgerson, D. J., R. E. Thomas, and D. M. Reid

1997 Mothers and daughters menopausal ages: Is there a link? European Journal of Obstetrics Gynecology and 
Reproductive Biology 74(1):63-66.

231. Torrens, Javier I., et al.

2009 Relative androgen excess during the menopausal transition predicts incident metabolic syndrome in midlife women: Study of Women's Health Across the Nation. Menopause-the Journal of the North American Menopause Society 16(2):257-264.

232. Treloar, A. E.

1981 Menstrual Cyclicity and the Pre-Menopause. Maturitas 3(3-4):249-264.

233. Tungphaisal, S., et al.

1991 Postmenopausal sexuality in Thai women. Asia Oceania J Obstet.Gynaecol. 17(2):143-146.

234. Turke, P. W.

1988 Helpers at the nest: childcare networks on Ifaluk.

In Human Reproductive Behaviour: A Darwinian perspective. L. Betzig, M. Borgerhoff Mulder, and P. W. Turke, eds. Pp. 173-188.Cambridge, UK: Cambridge University Press.

235. Turner, L. B.

2011 A meta-analysis of fat intake, reproduction, and breast cancer risk: an evolutionary perspective. Am.J Hum.Biol 23(5):601-608.

236. Ueno, A. and T. Matsuzawa

2004 Food transfer between chimpanzee mothers and their infants. Primates 45(4):231-239.

237. Utian, W. H.

2012 A decade post WHI, menopausal hormone therapy comes full circle--need for independent commission. Climacteric 15(4):320-325.

238. van Asselt, K. M., et al.

2004 Linkage analysis of extremely discordant and concordant sibling pairs identifies quantitative trait loci influencing variation in human menopausal age. American Journal of Human Genetics 74(3):444-453.

239. vanNoord, P. A. H., et al.

1997 Age at natural menopause in a population-based screening cohort: The role of menarche, fecundity, and lifestyle factors. Fertility and Sterility 68(1):95-102.

240. Videan, E., J. Fritz, C. B. Heward, and J. Murphy

2008 Reproductive aging in female chimpanzees (Pan troglodytes). In Primate reproductive aging: crosstaxon perspectives. S. Atsalis, S. W. Margulis, and P. R. Hof, eds. Pp. 103-118. Interdisciplinary Topics in Gerontology SeriesBasel: Karger.

241. Videan, E. N., J. Fritz, C. B. Heward, and J. Murphy

2006 The effects of aging on hormone and reproductive cycles in female chimpanzees (Pan troglodytes). Comparative Medicine 56(4):291-299.
242. Vitzthum, V. J.

2003 A number no greater than the sum of its parts: The use and abuse of heritability. Human Biology 75(4):539558.

243. Vitzthum, V. J.

2008 Evolutionary Models of Women's Reproductive Functioning. Annual Review of Anthropology 3753-73.

244. Vitzthum, V. J.

2009 The Ecology and Evolutionary Endocrinology of Reproduction in the Human Female. Yearbook of Physical Anthropology, Vol 52 5295-136.

245. Voland, E. and J. Beise

2002 Opposite effects of maternal and paternal grandmothers on infant survival in historical Krummhorn. Behav Ecol Sociobiol 52435-443.

246. Voorhuis, M., et al.

2010 Human studies on genetics of the age at natural menopause: a systematic review. Hum Reprod.Update. 16(4):364-377.

247. Walker, A. R. P., B. F. Walker, J. Ncongwane, and E. N. Tshabalala

1984 Age of Menopause in Black-Women in SouthAfrica. British Journal of Obstetrics and Gynaecology 91(8):797-801.

248. Walker, M. L. and J. G. Herndon

2008 Menopause in nonhuman primates? Biology of Reproduction 79(3):398-406.

249. Walker, R. and K. Hill

2003 Modeling growth and senescence in physical performance among the Ache of eastern Paraguay. American Journal of Human Biology 15(2):196-208.

250. Walsh, R. J.

1978 The age of the menopause of Australian women. Med J Aust. 2(5):181-2, 215.

251. Wayne, S. J., et al.

2008 Dietary fiber is associated with serum sex hormones and insulin-related peptides in postmenopausal breast cancer survivors. Breast Cancer Res Treat. 112(1):149158.

252. Weinberg, C. R., A. J. Wilcox, and D. D. Baird

1989 Reduced Fecundability in Women with Prenatal Exposure to Cigarette-Smoking. American Journal of Epidemiology 129(5):1072-1078.

253. Weismann, A.

1889 Essays upon heredity and kindred biological problems.Oxford: Clarendon Press.

254. Whelan, E. A., D. P. Sandler, D. R. Mcconnaughey, and C. R. Weinberg

1990 Menstrual and Reproductive Characteristics and 
Age at Natural Menopause. American Journal of Epidemiology 131(4):625-632.

255. White, Y. A. R., et al.

2012 Oocyte formation by mitotically active germ cells purified from ovaries of reproductive-age women. Nature Medicine 18(3):413-U176.

256. Williams, G. C.

1957 Pleiotropy, natural selection, and the evolution of senescence. Evolution 11398-411.

257. Williams, G. C. and R. M. Nesse

1991 The dawn of Darwinian medicine. Q.Rev Biol 66(1):1-22.

258. Wood, J. W.

1994 Dynamics of human reproduction: biology, biometry, demography.New York: Aldine de Gruyter.

259. Wu, X. W., D. M. Muzny, C. C. Lee, and C. T. Caskey 19922 Independent Mutational Events in the Loss of Urate Oxidase During Hominoid Evolution. Journal of Molecular Evolution 34(1):78-84.

260. Xue, F. and K. B. Michels

2007 Diabetes, metabolic syndrome, and breast cancer: a review of the current evidence. American Journal of Clinical Nutrition 86(3):823S-835S.

261. Yang, C. M. and C. H. Wu

2005 The Situational Fatigue Scale: A different approach to measuring fatigue. Quality of Life Research 14(5):13571362.

262. Yang, L. and K. H. Jacobsen

2008 A Systematic Review of the Association between Breastfeeding and Breast Cancer. Journal of Womens Health 17(10):1635-1645.

263. Zenzes, M. T.

2000 Smoking and reproduction: gene damage to human gametes and embryos. Human Reproduction Update 6(2):122-131. 